\title{
Superhydrophobic surfaces for corrosion protection: a review of recent progresses and future directions
}

\author{
Dawei Zhang, Luntao Wang, Hongchang Qian, Xiaogang Li
}

(C) The Author(s) 2015. This article is published with open access at Springerlink.com

\begin{abstract}
Due to their superior water-repelling effects, superhydrophobic surfaces have received increasing attention as a promising solution to corrosion of metallic materials. The present article introduces the fundamental theories behind superhydrophobicity followed by a comprehensive review of the recent progresses of this rapidly growing field over the past 5 years. A critical discussion over anticorrosion mechanisms of superhydrophobic surfaces is also provided. For many realistic applications, future efforts are pressingly demanded to prolong the corrosion resistance of these superhydrophobic surfaces. To this end, several important strategies and examples in designing stable, selfhealable, or inhibitor-loaded superhydrophobic surfaces are discussed.
\end{abstract}

Keywords Superhydrophobic surface, Corrosion protection, Wetting, Microstructures, Self-healing

\section{Introduction}

Inspired by nature (e.g., lotus leaves, ${ }^{1}$ cicada's wing, ${ }^{2}$ mosquito compound eyes ${ }^{3}$ and rose petals ${ }^{4}$ ), superhydrophobic surfaces are generally defined as surfaces which have water contact angles $(\theta)$ higher than $150^{\circ}$. Depending on the contact angle hysteresis (CAH) values, superhydrophobicity can be further categorized into different states. ${ }^{5}$ While some superhydrophobic surfaces might exhibit high $\mathrm{CAH}$ and strong adhesion to water (also known as adhesive superhydrophobicity), ${ }^{4,6,7}$ the surfaces of interest in this paper refer to those having very low CAHs and thus high water repellency.

D. Zhang, L. Wang, H. Qian, X. Li ( $\bowtie)$

Corrosion \& Protection Center, University of Science \&

Technology Beijing, Beijing 100083,

People's Republic of China

e-mail: lixiaogang@ustb.edu.cn
These surfaces have received continued attention for their broad applications, such as self-cleaning, antifogging and frosting, and drag reduction. With the unique water-repelling feature of these surfaces, they are also capable of reducing deterioration of metal surfaces caused by corrosion in aqueous media. In recent years, improving the corrosion resistance of metallic materials by surface superhydrophobization has become one of the hottest research areas in corrosion and protection. Compared to existing literature which has frequently reviewed the theories, preparation, and applications of superhydrophobic surfaces, ${ }^{8-15}$ this review mainly focuses on the most recent developments of superhydrophobic surfaces for anticorrosion purposes. The authors review the typical preparation techniques of superhydrophobic anticorrosive surfaces and their anticorrosive performance, and provide a critical discussion of some mechanistic aspects of corrosion protection based on superhydrophobicity. Finally, some important future perspectives are also highlighted to provide references for developing superhydrophobic surface with long-lasting corrosion resistance.

\section{The theory of superhydrophobic surfaces}

\section{Wettability of a smooth surface}

Wettability is the spreadability of water on a solid surface. On a flat surface (Fig. 1a), the contact angle is fixed and determined by surface free energy, according to Young's equation ${ }^{16}$

$\cos \theta_{0}=\frac{\gamma_{\mathrm{SG}}-\gamma_{\mathrm{SL}}}{\gamma_{\mathrm{LG}}}$

where $\theta_{0}$ is the contact angle of smooth surface, and $\gamma_{\mathrm{SG}}, \gamma_{\mathrm{SL}}$, and $\gamma_{\mathrm{LG}}$ are solid-gas, solid-liquid, and liquidgas interfacial tension, respectively. 
(a)

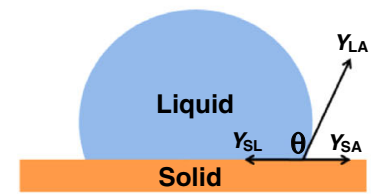

(b)

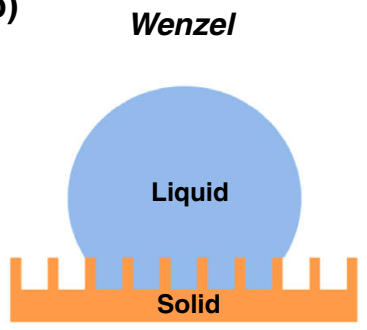

(c)

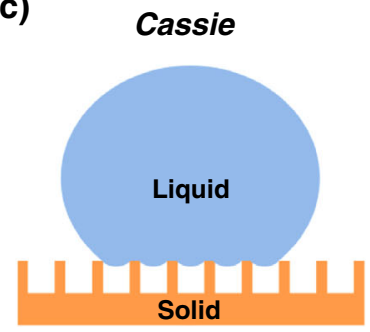

Fig. 1: Wetting states: (a) Young's; (b) Wenzel; (c) Cassie

\section{Wettability of a rough surface}

To quantitatively characterize the wettability of a rough surface, Wenzel $^{17}$ and Cassie $^{18}$ modified Young's equation in the 1940s. Wenzel introduced the concept of surface roughness to the wettability theory and established the Wenzel model, which can quantitatively calculate the contact angle of a droplet on a homogeneous rough surface. In Wenzel mode, the droplet completely fills the microscopic grooves of the rough surface, which increases the actual contact area between water and surface (Fig. 1b). Thus, the hydrophobic effect is geometrically amplified, further increasing the contact angle. The Wenzel equation may be expressed as

$\cos \theta_{\mathrm{W}}=r \cos \theta_{0}$

where $\theta_{0}$ is the intrinsic contact angle (Young's contact angle), $\theta_{\mathrm{W}}$ is the apparent contact angle (Wenzel's contact angle), and $r$ is roughness factor, which is defined as the ratio of the actual surface area to the projected area.

Cassie and Baxter have modified the theory of wetting by introducing the concept of area fraction $(f)$, which refers to the proportion of the contact area of each phase (component) in the general contact area. If a composite surface consists of two different components, the intrinsic contact angles of two components are $\theta_{1}$ and $\theta_{2}$, respectively, and the fraction of each component in the general area is $f_{1}, f_{2}$, and $f_{1}+f_{2}=1$. The apparent contact angle may be calculated by Cassie-Baxter equation

$\cos \theta_{\mathrm{CB}}=f_{1} \cos \theta_{1}+f_{2} \cos \theta_{2}$

When there is air remaining in the grooves of a rough surface, a droplet cannot fill the grooves, and the material surface consists of two phases: solid and air (Fig. 1c). Now, the actual contact area of droplet includes the contact area between droplet and air and the contact area between droplet and solid part. Given the fact that the intrinsic contact angle between droplet and air is $180^{\circ}$, the apparent contact angle can be determined using the following simplified equation: $\cos \theta_{\mathrm{CB}}=f_{\mathrm{SL}} \cos \theta_{0}+f_{\mathrm{SL}}-1$

With increasing roughness factor or surface hydrophobicity, the droplet becomes more favorable of resting on the rough surface in Cassie mode. In this case, by adjusting the microscopic morphology of material surface or reducing the proportion of solid-liquid contact interface, the superhydrophobic state of $\theta>150^{\circ}$ may be realized. ${ }^{8}$ Furthermore, $\mathrm{CAH}$ and roll-off angle become smaller, and the self-cleaning capacity of the surface is enhanced.

\section{Application of superhydrophobic surfaces for corrosion protection}

Increasing surface hydrophobicity often results in decreased corrosion rate of metals by limiting their interactions with corrosive species, such as water and ions. For organic anticorrosive coatings, this would retard the diffusion process of water molecules and prolong the coating's protectiveness against corrosion of underlying metal substrates. ${ }^{19}$ As previously explained, the hydrophobicity of a material surface mainly depends on its intrinsic chemical properties and surface microstructures. To improve surface hydrophobicity, incorporation with low surface energy materials is often first considered. ${ }^{20-24}$ For example, the surface energy of silicone resin may be as low as $22 \mathrm{mN} / \mathrm{m}^{25}$ Fluorine-containing resin is of even lower surface energy $\left(\sim 10 \mathrm{mN} / \mathrm{m}^{26}\right)$. However, water contact angle of smooth hydrophobic surface can hardly exceed $120^{\circ}$. By introducing surface roughness, the hydrophobicity of a surface can be further increased, with contact angle even higher than $150^{\circ}$, achieving the superhydrophobic state. To enhance the corrosion resistance of metallic materials, different methods have been used to create rough microstructures on their surfaces to endow superhydrophobicity. Among these methods, the most common ones include wet chemical reaction, etching, hydrothermal method, anodization, electrodeposition, sol-gel method, nanocomposite coating, and templating. 


\section{Wet chemical reaction}

This method covers a broad range of different chemical reactions by which the microstructures required for superhydrophobic surfaces are directly synthesized. ${ }^{27-38}$ The hydrophobic components can be introduced during the synthesis or as post-treatments. Yin et al. treated copper surface with a tetradecanoic acid solution to produce flower-like microstructures. ${ }^{27} \mathrm{By}$ increasing the solution concentration, the surface was changed from hydrophilic to hydrophobic and eventually to superhydrophobic, and its anticorrosive capacity against seawater accordingly increased. By immersing in cerium nitrate hexahydrate solution, Ishizaki generated nanostructured cerium oxide films on the surface of magnesium alloy. ${ }^{29}$ After fluoroalkyl silane (FAS) modification, a superhydrophobic surface was created with water contact angle reaching $153.4^{\circ}$. After $24 \mathrm{~h}$ of immersion in $5 \mathrm{wt} \% \mathrm{NaCl}$ solution, EIS measurements showed that the low-frequency impedance modulus of the superhydrophobic surface was five orders of magnitude higher than the untreated surface. From the polarization curves, the corrosion current density of superhydrophobic magnesium alloy surface was much smaller than that of untreated surface. These results suggest that after superhydrophobization, the anticorrosive performance of magnesium alloy was greatly improved. In a recent study, superhydrophobic films were also built up on the surface of magnesium alloy by a simple immersion process in a solution containing ferric chloride, deionized water, tetradecanoic acid, and ethanol (Fig. 2). ${ }^{35}$ Electrochemical tests showed that after $24 \mathrm{~h}$ of immersion in $3.5 \%$ $\mathrm{NaCl}$ solution, the superhydrophobic magnesium alloy surface had a far lower corrosion current density than that of bare substrate, exhibiting good anticorrosive capacity. The main advantage of wet chemical reactions is that the fabrication of superhydrophobic surfaces requires only simple solution immersion. This also permits a certain level of flexibility since the method can be applied to substrates of different shapes and sizes. ${ }^{39,40}$ The most notable limitation associated with wet chemical reactions (as well as many other fabrication methods for superhydrophobic surfaces) is the use of expensive low surface energy materials. ${ }^{41,42}$

\section{Etching}

The microstructures can be also obtained by selectively chemical etching of dislocations or impurities on metal surfaces. ${ }^{43-51}$ This is often followed by grafting low surface energy materials to achieve superhydrophobicity. Liu et al. etched $\mathrm{Mg}-\mathrm{Li}$ alloy using $0.1 \mathrm{~mol} / \mathrm{L}$ hydrochloric acid. After immersing in ethanol solution containing $1 \mathrm{wt} \%$ FAS for $12 \mathrm{~h}$ and then a heat treatment at $100^{\circ} \mathrm{C}$, the obtained surface exhibited a long-lasting superhydrophobicity which was maintained even after 180 days in an atmospheric corrosion environment. ${ }^{43}$ By chemical etching in sodium hypochlorite and a following hydrophobization with hexadecyltrimethoxysilane, superhydrophobic aluminum surface was also fabricated to show enhanced corrosion resistance as confirmed by the polarization curves and long-term immersion in $3.5 \mathrm{wt} \% \mathrm{NaCl}$ solution (Fig. 3). ${ }^{50}$ Recently, Wang et al. prepared superhydrophobic steel surfaces by etching in $\mathrm{H}_{2} \mathrm{O}_{2} /$ $\mathrm{HCl} / \mathrm{HNO}_{3}$ solution and subsequently treating with FAS. $^{51}$ By varying the $\mathrm{acid} / \mathrm{H}_{2} \mathrm{O}_{2}$ volume ratio, surfaces with a gradient of wettability were obtained. Polarization curves confirmed the superior anticorrosive performance of the superhydrophobic surface was attributed to air inclusion in the microstructures under water. Compared to wet chemical reactions, the superhydrophobic microstructures are directly etched out from the bulk materials and are thus expected to be more stable against mechanical forces. ${ }^{52}$ However, the etching processes are carried out in harsh conditions, such as strong acids, which are hazardous to the environment and the health of the operators. ${ }^{53,54}$

\section{Hydrothermal method}

Similar to the two methods above, the hydrothermal method is another important top-down approach for fabrication of superhydrophobic anticorrosive surfaces. ${ }^{55-61}$ Here, the surface microstructures are synthesized from an aqueous environment under elevated heat and/or pressure. Hydrothermal methods are considered more environmentally friendly since the chemical used to create surface microstructures is only $\mathrm{H}_{2} \mathrm{O}$ or dilute $\mathrm{H}_{2} \mathrm{O}_{2}{ }^{58} \mathrm{Li}$ et al., reported a hydrothermal method to produce superhydrophobic zinc surface using a two-step approach: (1) autoclaving zinc in pure water at $120^{\circ} \mathrm{C}$ for surface roughening; (2) immersing in ethanol solution containing $1 \mathrm{H}, 1 \mathrm{H}, 2 \mathrm{H}, 2 \mathrm{H}$-perfluorooctyltriethoxysilane (PFOTES) for surface hydrophobization. ${ }^{57}$ From the viewpoint of corrosion protection, hydrothermal methods are also more favored than chemical etching because of the formation of oxide or hydroxide protective layers. For example, $\mathrm{Ou}$ et al. used hydrothermal methods to prepare oxide or hydroxide layers on the surface of light alloys, such as magnesium, aluminum, and titanium alloys and grafted with PFOTES to endow superhydrophobicity. ${ }^{58}$ Separately, they applied the acid etching method to produce roughness on the surface of these alloys. After treatment with perfluorooctyl trichlorosilane (PFOTS), superhydrophobic surfaces were also obtained. As shown in Fig. 4, polarization measurements revealed that corrosion current density can be drastically decreased after superhydrophobization. Compared with etching method, the superhydrophobic structure prepared through hydrothermal method exhibited even better corrosion resistance (higher corrosion potential and lower corrosion current density), which was co-contributed by 
(a)

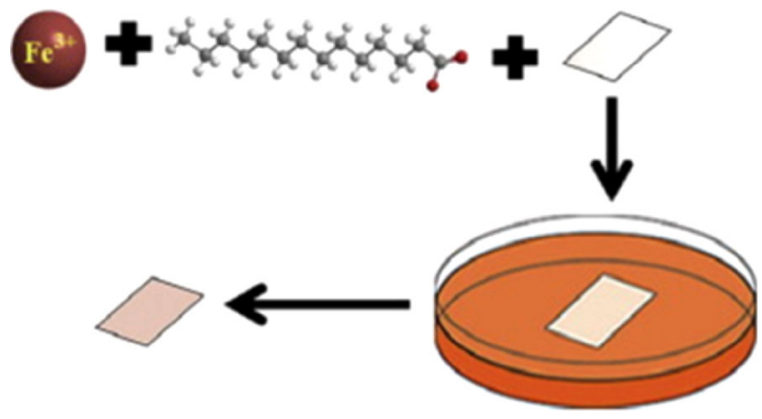

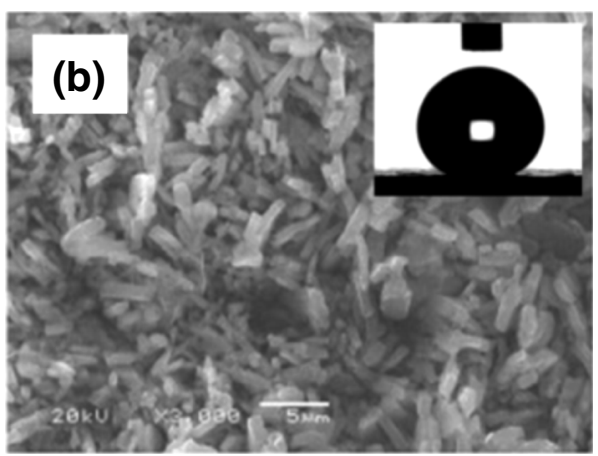

(c)

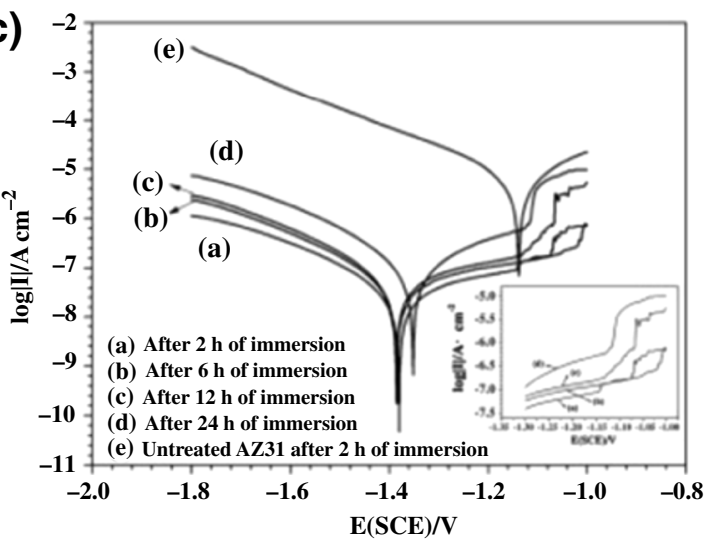

(d)

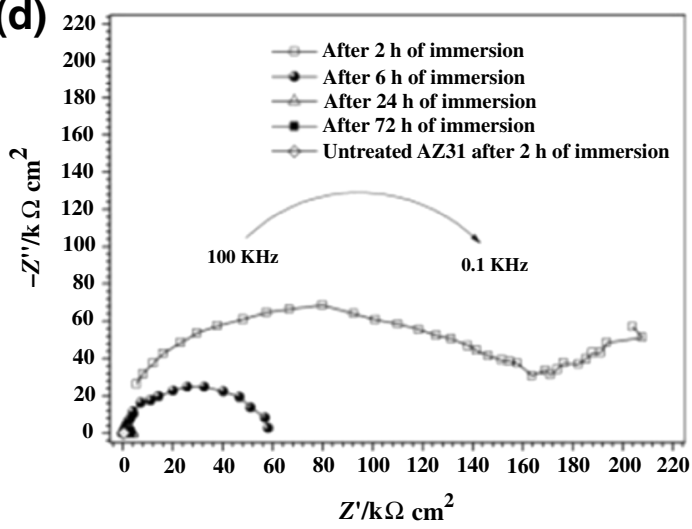

Fig. 2: (a) Schematic illustration of the process to synthesize superhydrophobic tetradecanoic acid iron surface on AZ31 magnesium alloy; (b) SEM morphology of the superhydrophobic surface; (c) Polarization curves of the untreated and superhydrophobic surfaces after immersion in $3.5 \mathrm{wt} \% \mathrm{NaCl}$ solution for different time and the enlarged anodic curves; (d) Nyquist plots of the EIS spectra for the untreated and superhydrophobic surfaces ${ }^{35}$

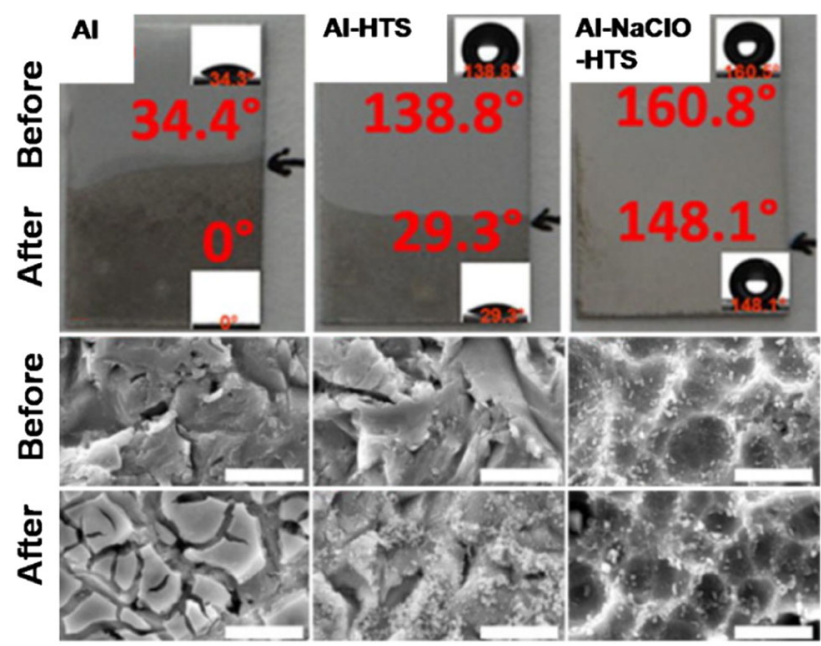

Fig. 3: Bare aluminum (left), aluminum after hydrophobic treatment (middle), and etched aluminum after hydrophobic treatment (right) before and after corrosion in $3.5 \mathrm{wt} \% \mathrm{NaCl}$ solution for 7 days. ${ }^{50}$ Scale bar is $10 \mu \mathrm{m}$

the air cushion as resulted from the surface hydrophobicity and the barrier effect from the hydroxide layer grown on the metal substrates.

\section{Anodization}

By means of anodization, micro or nanoscaled surface roughness can also be effectively generated to prepare superhydrophobic anticorrosive surfaces. ${ }^{62-69}$ Stable superhydrophobic films were prepared by anodization of titanium and subsequent immersion in a methanol solution of hydrolyzed PFOTES (Fig. 5). ${ }^{63}$ The water contact angle on the obtained surface has reached $160^{\circ}$. Electrochemical impedance spectroscopy (EIS) results showed that a high corrosion resistance can be retained after immersion in $3.5 \mathrm{wt} \% \mathrm{NaCl}$ solution for 90 days. Xiao et al. anodized copper surface in $\mathrm{KOH}$ solution to generate $\mathrm{Cu}(\mathrm{OH})_{2}$ nanoneedle arrays. ${ }^{69}$ After dehydration, $\mathrm{CuO}$ nanoneedle arrays were formed and were grafted with FAS to achieve superhydrophobicity. The superhydrophobicity was found stable at $\mathrm{pH} 1-13$. It was largely maintained in pure water and $1.5 \mathrm{wt} \%$ $\mathrm{NaCl}$ solution for at least 7 days but substantially decreased in $3.5 \mathrm{wt} \% \mathrm{NaCl}$ solution due to the loss of the hierarchical microstructures in nanoneedle arrays. One of the major advantages of anodization techniques is its high efficiency in producing surface microstructures. For instance, the microstructures needed for superhydrophobic aluminum surfaces were obtained by an anodization for only $40 \mathrm{~s}$ in $0.3 \mathrm{~mol} / \mathrm{L}$ oxalic acid at $1^{\circ} \mathrm{C}$ and $130 \mathrm{~V} .^{70}$ 
(a)
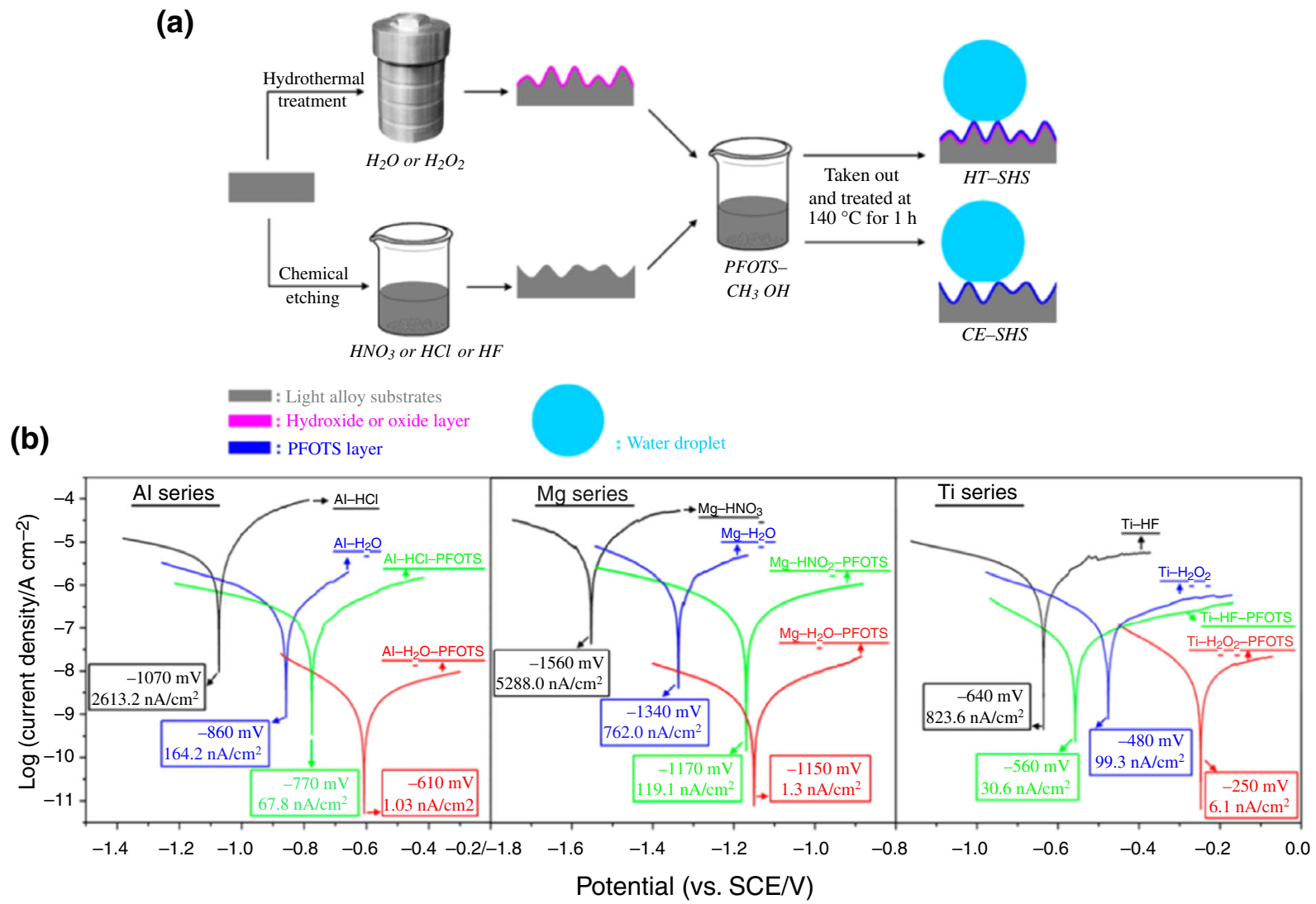

Fig. 4: (a) Schematic illustration for the preparation process of superhydrophobic surfaces on light alloys based on hydrothermal or chemical etching methods; (b) Tafel plots of etched (black), hydrothermally treated (blue), etched + hydrophobized (green), and hydrothermally treated + hydrophobized (red) surfaces. The corresponding corrosion potential $\left(E_{\text {corr }}\right)$ and corrosion current density $\left(I_{\text {corr }}\right)$ were denoted in the rectangles ${ }^{58}$ (Color figure online)

\section{Electrodeposition}

In electrochemical deposition, a thin coating is deposited onto a conductive substrate from a solution containing ions or charged micro/nanoparticles. ${ }^{53,71-77}$ It is an emerging technology for fabrication of superhydrophobic anticorrosive surfaces with major advantages such as high efficiency and scalability. For example, using a traditional Watts bath and a platinum anode, a pine-cone-like hierarchical micronanostructured nickel coating was electrochemically deposited onto copper cathode. ${ }^{74}$ After modification with (heptadecafluoro-1, 1, 2, 2-tetradecyl) triethoxysilane, the obtained superhydrophobic surface showed largely improved corrosion resistance as determined by polarization curves and EIS measurements. The electrodeposition process can be further simplified so that roughness creation and surface hydrophobization can be finished in a single step. Cerium myristate surface with a hierarchical micro/nanoscale particulate structure was prepared on magnesium alloy via a rapid onestep electrochemical deposition method in an ethanol solution containing cerium nitrate hexahydrate and myristic acid (Fig. 6) ${ }^{76}$ The surface shows superhy- drophobicity and high corrosion resistance against various corrosive environments. Liu et al. reported a similar approach where a superhydrophobic surface was prepared on copper by electrochemical deposition in ethanol solution containing cerium chloride and myristic acid. ${ }^{77}$

\section{Sol-gel method}

Inorganic-organic sol-gel coatings can also be engineered with superhydrophobicity for anticorrosion purposes. ${ }^{24,78-83}$ Sol-gel processes generally do not require high temperature or high pressure and can be readily applied on a variety of substrates. ${ }^{40,84} \mathrm{~A}$ superhydrophobic silica coating was prepared by dipcoating copper substrate in a sol-gel solution containing methyltriethoxysilane, methanol, water, and ammonia. ${ }^{78}$ The obtained coating exhibited a water contact angle of $155^{\circ}$ and roll-off angle lower than $7^{\circ}$. Such superhydrophobicity was maintained after immersion in $50 \mathrm{wt} \%$ hydrochloric acid for $100 \mathrm{~h}$. After exposure to the air for 90 days, the coating still remained hydrophobic showing a contact angle $>90^{\circ}$. 

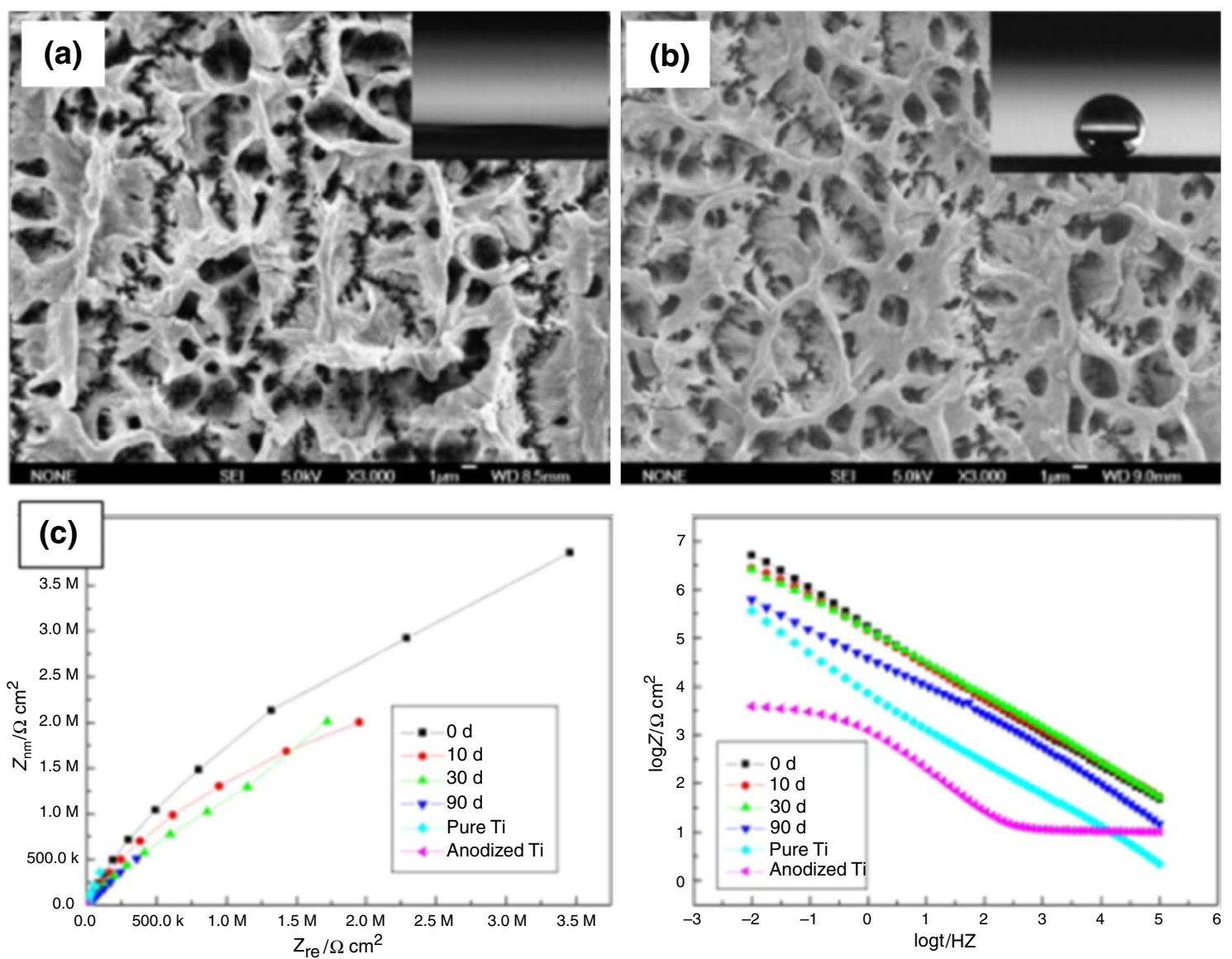

Fig. 5: SEM images and wetting behaviors of (a) the as-anodized and (b) the superhydrophobic titanium surfaces; (c) Nyquist diagrams (left) and Bode diagrams (right) from EIS studies for superhydrophobic surface after immersion in $3.5 \mathrm{wt} \% \mathrm{NaCl}$ solution for different time ${ }^{63}$
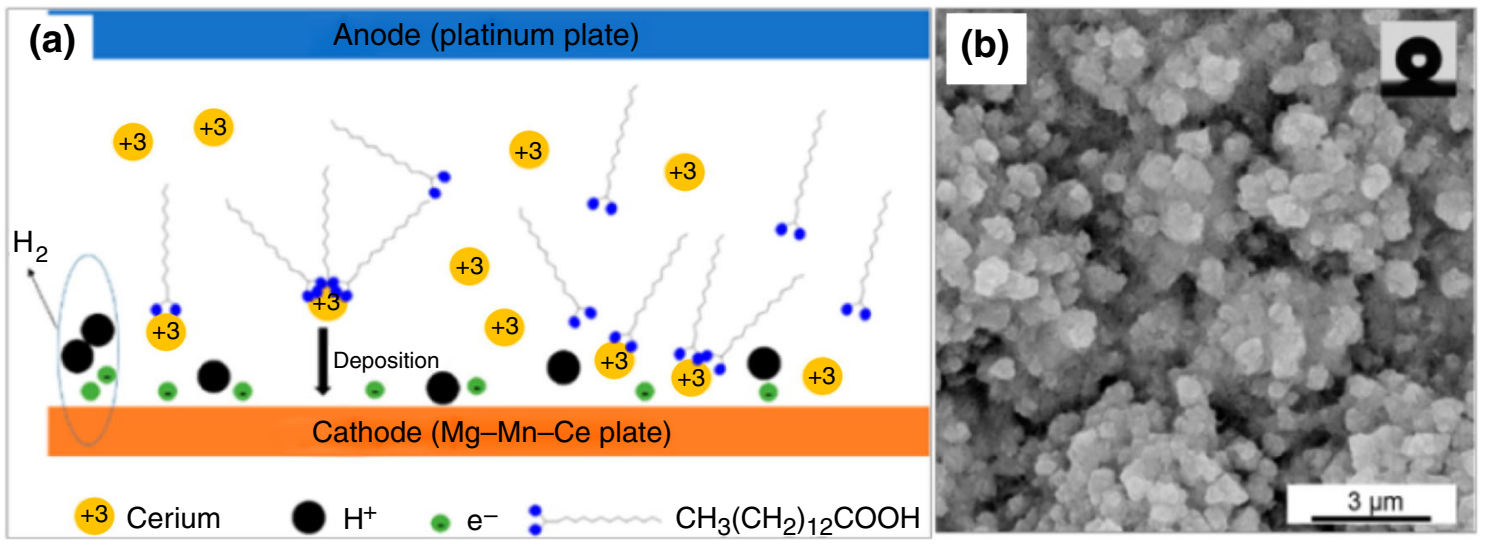

Fig. 6: (a) Schematic illustration of the electrodeposition process and (b) representative SEM morphology of the obtained superhydrophobic surface ${ }^{76}$

$\mathrm{Hu}$ and coworkers developed an interesting electrodeposition assisted sol-gel approach (Fig. 7). ${ }^{81}$ On mild steel, the accelerated growth of sol-gel coating was achieved by the enhanced sol-gel condensation process due to the increased $\mathrm{pH}$ in solution near the substrate applied with cathodic potentials. The corrosion resistance of the obtained superhydrophobic coating was confirmed by much higher impedance modulus in EIS results. Because of the high strength of the $\mathrm{Si}-\mathrm{O}$ bond, inorganic-organic sol-gel coatings can demonstrate 

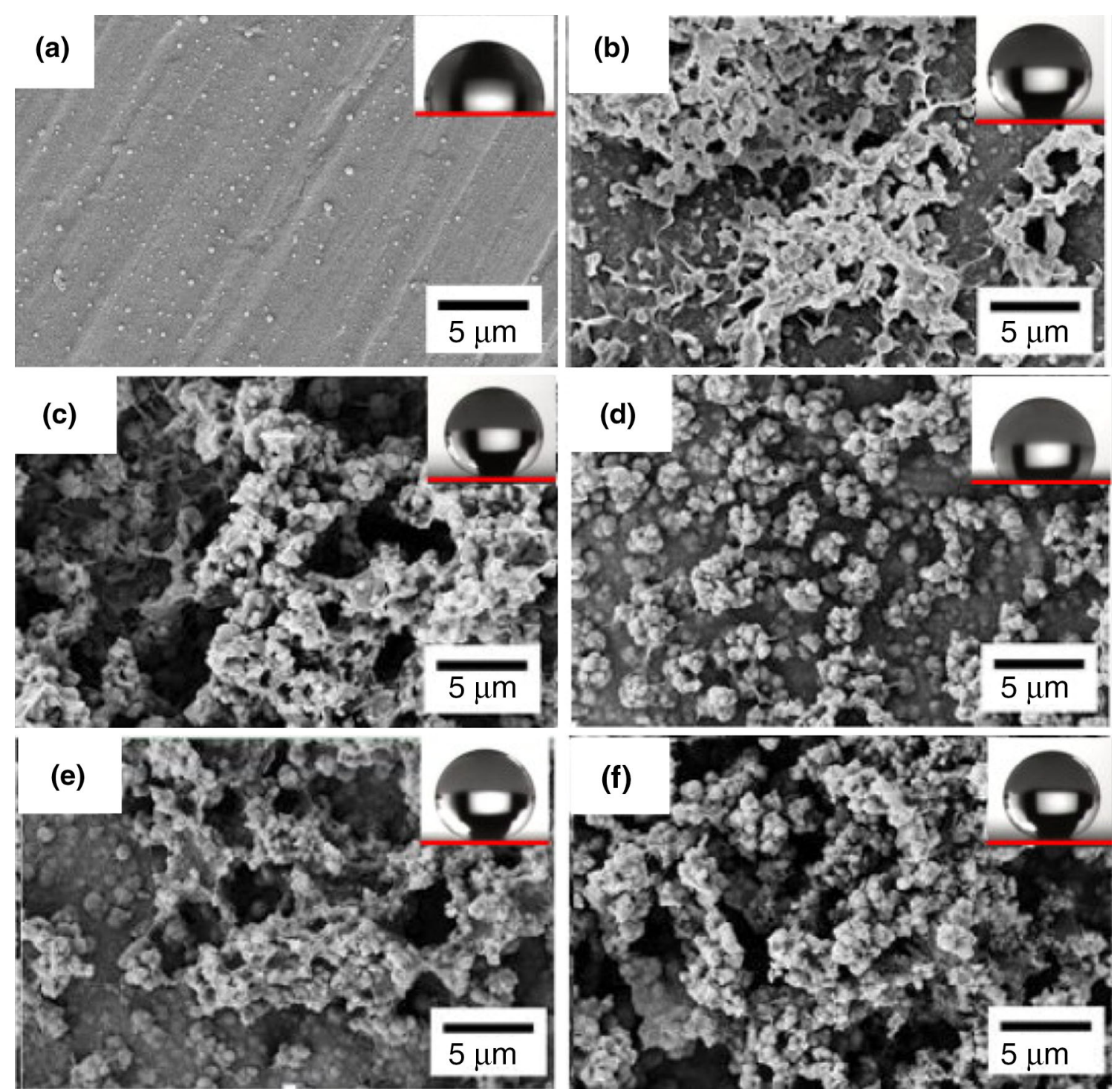

Fig. 7: SEM morphologies and wetting behaviors of electrodeposited hybrid silica sol-gel films prepared at -1.3 V vs Ag/ $\mathrm{AgCl}$ for (a) $20 \mathrm{~s}$, (b) $100 \mathrm{~s}$, and (c) $300 \mathrm{~s}$; and deposited for $300 \mathrm{~s}$ at (d) $-1.0 \mathrm{~V}$, (e) $-1.2 \mathrm{~V}$, and (f) $-1.5 \mathrm{~V} \mathrm{vs} \mathrm{Ag} / \mathrm{AgCl}{ }^{81}$

better thermal and UV stability than organic coatings. For example, the sol-gel coatings made from tetraethoxysilane (TEOS) and trifluoropropylmethoxysilane (TFPS) precursors can maintain excellent superhydrophobicity even after $1000 \mathrm{~h}$ of accelerated UV exposure test. ${ }^{85}$

\section{Nanocomposite coatings}

Superhydrophobic anticorrosive surfaces can also be obtained with a bottom-up approach by means of nanocomposite coatings. ${ }^{41,86-90}$ Here, surface roughness required for superhydrophobicity is created by nanoparticles while surface hydrophobicity can be imparted by both nanoparticles and organic resins which also serve as binders to connect nanoparticles.
Many of the superhydrophobic nanocomposite coatings are sprayable and, therefore, share a unique advantage in the adaptability for large-scale fabrication. $\mathrm{Xu}$ et al. prepared hydrophobic thiolated Ag$\mathrm{TiO}_{2}$ nanoparticles and mixed them with ethanol solution containing polymethylmethacrylate. ${ }^{86}$ After spraying the suspension against the copper substrate and drying, a superhydrophobic coating with enhanced corrosion protection was obtained. $\mathrm{ZnO}$ nanoparticles, modified by hydrophobic stearic acid, were mixed with fluorinated polysiloxane (FPHS) and sprayed on steel substrate (Fig. 8). ${ }^{90}$ The prepared superhydrophobic coating displayed superior anticorrosive performances on both FPHS coating and $\mathrm{ZnO}$ coating, as indicated by the lower corrosion rate calculated from polarization curves and the larger capacitive arc from EIS spectra. When a strong bonding is established between 


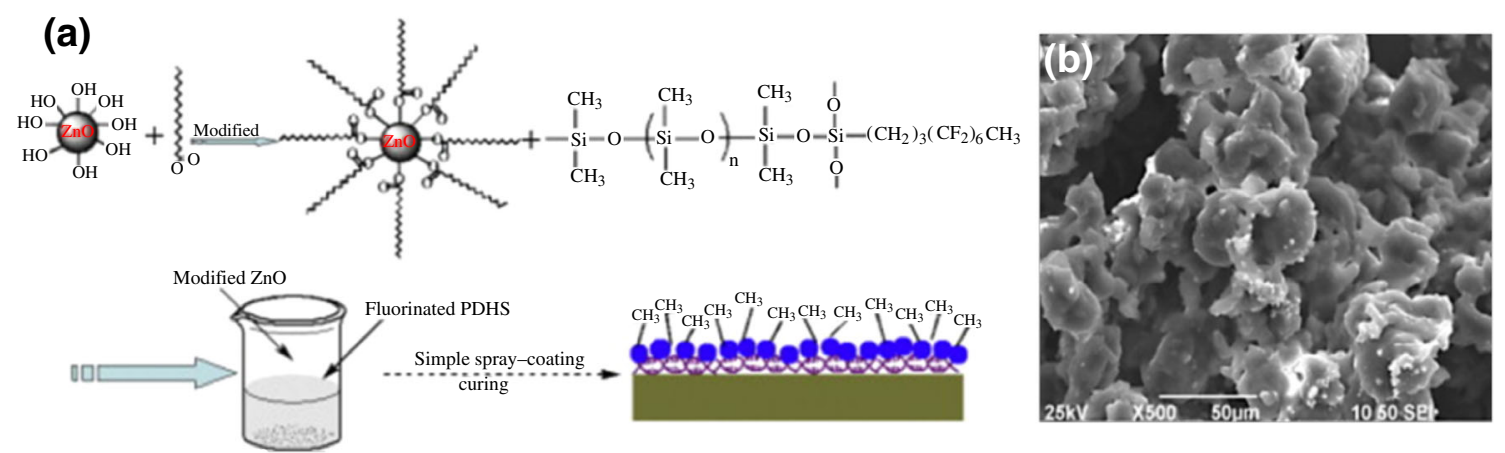

Fig. 8: (a) Superhydrophobic ZnO/FPHS nanocomposite coating; (b) SEM morphology of coating surface ${ }^{90}$

nanoparticles and resins, the mechanical durability of the coating can be significantly improved. ${ }^{91,92}$ Using epoxy adhesives, $\mathrm{SiO}_{2}$ nanoparticles were anchored on a sand-blasted rough epoxy coating. The surface hydrophobicity of the coating can be largely retained even after a 250 min scouring test with water stream at $10 \mathrm{~m} / \mathrm{s}^{91}$ Another benefit of nanocomposite coatings comes from the diversity of nanoparticles through which the mechanical, electrical, optical, and other properties of the coatings can be conveniently tuned. ${ }^{42}$

\section{Templating}

Templating based on soft lithography is a cost-effective micro/nanofabrication technique with the advantage in precise control of micro/nanostructures by replicating a template. ${ }^{93}$ For example, Yeh and coworkers have casted and cured polydimethylsiloxane onto superhydrophobic Xanthosoma sagittifolium leaves and transferred the micropapillary structures to produce a series of superhydrophobic polymer-based coatings on mild steels (Fig. 9). ${ }^{94-97}$ Compared to flat coating, the microstructured coating exhibits improved barrier performance against water thanks to the inclusion of air within the microstructures, thereby improving the protection capability of layer for metal substrate. In addition, nanoparticles, such as clays ${ }^{98}$ or graphene, ${ }^{99}$ have been incorporated to these coatings to decrease oxygen permeability. The templating method can be applied on diverse types of polymers and is capable of making very fine surface microstructures down to only a few nanometers. ${ }^{8}$ However, the limited sizes of the templates restrict the use of this method for large-scale applications. In addition, the templating method might not be able to produce excessively complex surface microstructures as damages may occur on both the samples and the templates during the peeling off procedure. ${ }^{11}$

\section{Mechanistic aspects}

Although superhydrophobic surfaces have received rapidly increasing popularity for their high corrosion resistance, existing studies mostly focused on their fabrications but lacked in-depth discussion over the electrochemical behaviors and anticorrosion mechanisms. The microstructures of a superhydrophobic surface are capable of trapping air films, which greatly reduce the contact area between droplet and surface. Thus, it is generally believed that superhydrophobic surfaces can inhibit atmospheric corrosion by hindering the formation of an electrolyte film. ${ }^{46,71}$ Meanwhile, because of the air films, water droplets and dissolved corrosive species can hardly stay on a surface. This is expected to be useful for corrosion protection under rainy atmospheric environments. ${ }^{100}$ However, it should be noted that the water repellency of superhydrophobic surfaces depends on the relative dimensions between water droplets and surface microstructures. ${ }^{101}$ In actual atmospheric environment, the ultrafine droplets in the water vapor may directly condense within the surface microstructures. As a result, the protective air films cannot be formed. To solve this problem, superhydrophobic microstructures of a much finer scale and/or a much higher aspect ratio were recommended, ${ }^{102,103}$ even though this may raise other issues, such as low mechanical durability of the microstructures. ${ }^{52}$ According to Zhang and co-workers, superhydrophobic surfaces can also effectively inhibit atmospheric corrosion induced by the deliquescence of salt particles. ${ }^{68,104}$ On a horizontal superhydrophobic surface, saline solution from the deliquescent salt can hardly spread and, therefore, remains in a spherical shape until the salt is completely dissolved (Fig. 10). On a tilted surface, the salt particles tend to slip off due to the highly lubricating effect of trapped air (Fig. 11).68,104 However, this special self-cleaning effect also depends on the size of the microstructures. The saline water from the deliquesced salt which rolls off on top of small microstructures $\left(\sim 5 \mu \mathrm{m}^{104}\right)$ can penetrate large microstructures $\left(\sim 30 \mu \mathrm{m}^{105}\right)$, leading to a much lower corrosion resistance. Moreover, the salt particles deposited from the actual marine atmosphere can be very small and easily reach into the microstructures of superhydrophobic surfaces. Therefore, deliquescence of salt is more likely to induce a Wenzel contact which pins the droplet to the surface. 


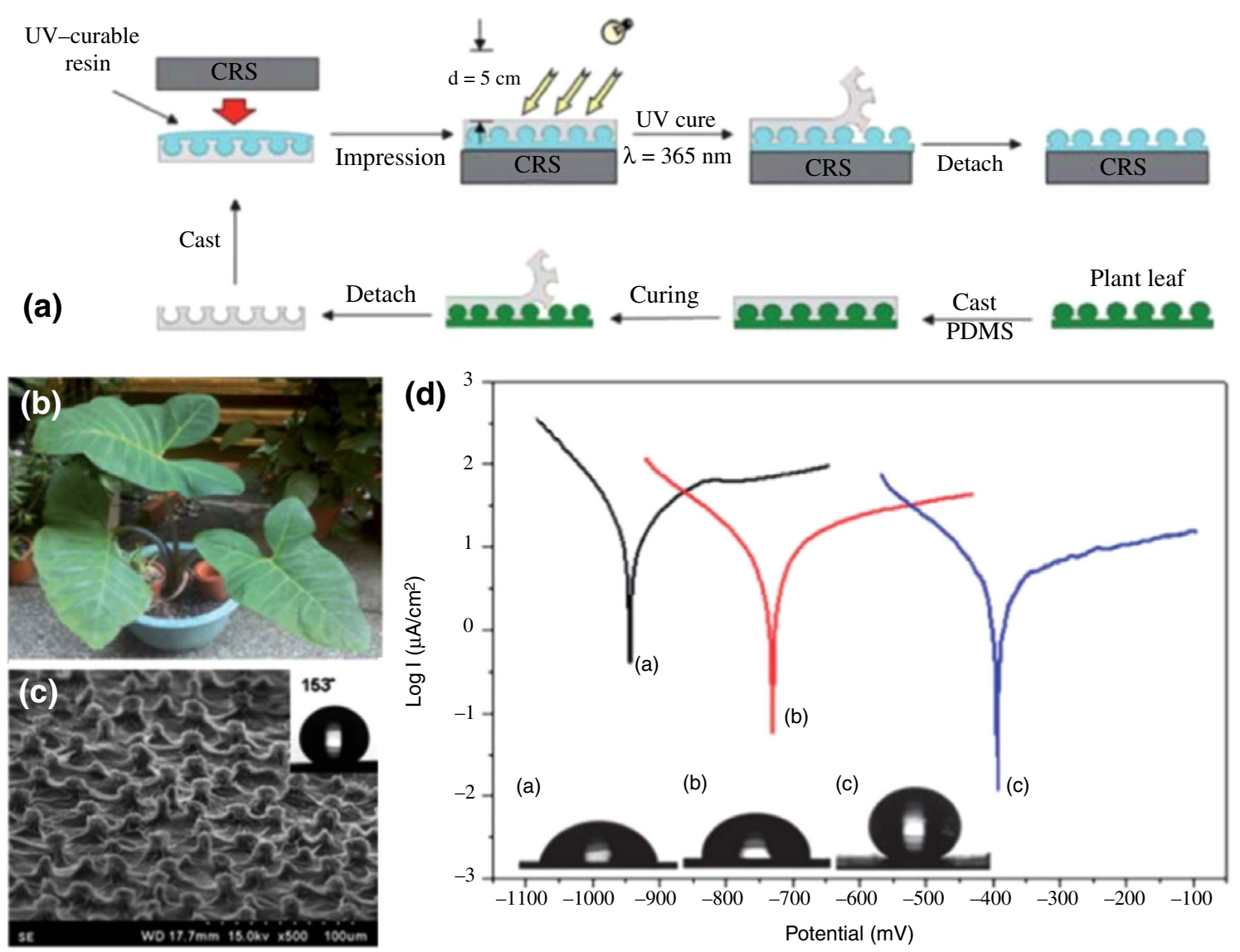

Fig. 9: (a) Preparation process for the superhydrophobic polymer surfaces by templating using a Xanthosoma sagittifolium leaf; (b) Xanthosoma sagittifolium leaves; (c) SEM image of micropapillary structures on the superhydrophobic polymer surface; (d) Tafel plots for bare steel, steel with flat coating and steel with superhydrophobic coating (left to right) ${ }^{96}$

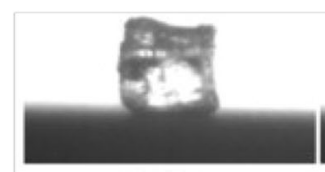

(a)

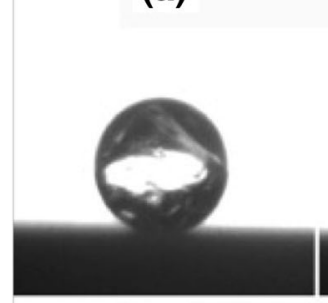

(e)

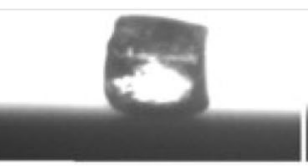

(b)

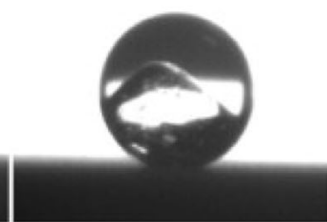

(f)

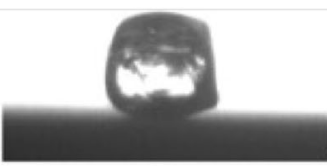

(c)

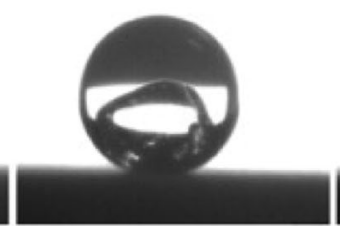

(g)

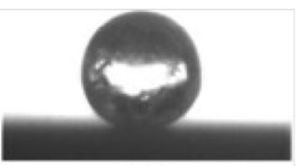

(d)

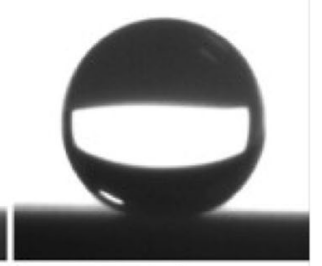

(h)

Fig. 10: Deliquescence of an $\mathrm{NaCl}$ particle on horizontal superhydrophobic surface in an atmospheric condition of $\mathrm{RH}=90 \%$ after (a) $0 \mathrm{~min}$, (b) $2 \mathrm{~min}$, (c) $4 \mathrm{~min}$, (d) $8 \mathrm{~min}$, (e) $12 \mathrm{~min}$, (f) $16 \mathrm{~min},(\mathrm{~g}) 20 \mathrm{~min}$, and (h) $40 \mathrm{~min}{ }^{104}$

For a superhydrophobic surface immersed in water, the air film captured in the microstructures forms an additional nonconductive barrier, which to some extent isolates the surface from surrounding water and improves the overall anticorrosive performance
(Fig. 12a). The existence of the air films has been confirmed visibly ${ }^{105,106}$ and by confocal Raman spectroscopy. ${ }^{107}$ Electrochemically, such air films have been correlated with the unexpected large fluctuation when measuring the open circuit potentials (OCP) 


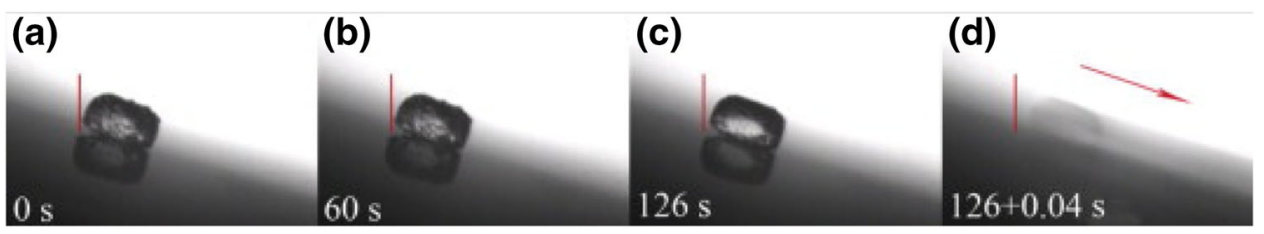

Fig. 11: Deliquescence of an $\mathrm{NaCl}$ particle on tilted superhydrophobic surface in an atmospheric condition of $\mathrm{RH}=90 \%$ after (a) $0 \mathrm{~s}$, (b) $60 \mathrm{~s}$, (c) $126 \mathrm{~s}$, and (d) $126+0.04 \mathrm{~s}^{68}$

(a)

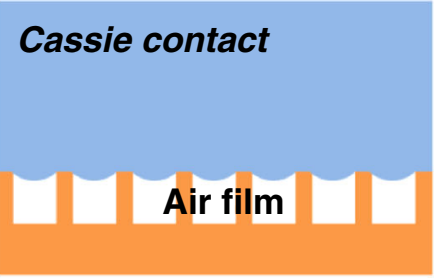

(b)

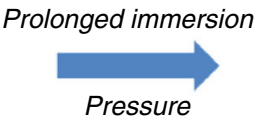

Pressure

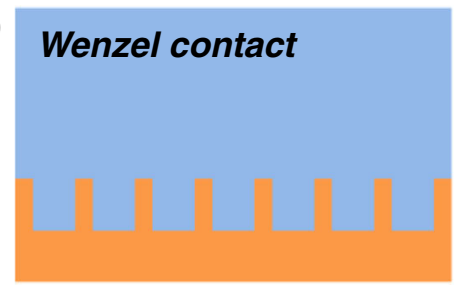

Fig. 12: (a) Superhydrophobic surface trapping air films when immersed; (b) Penetration of electrolyte through air films after prolonged immersion or under pressure
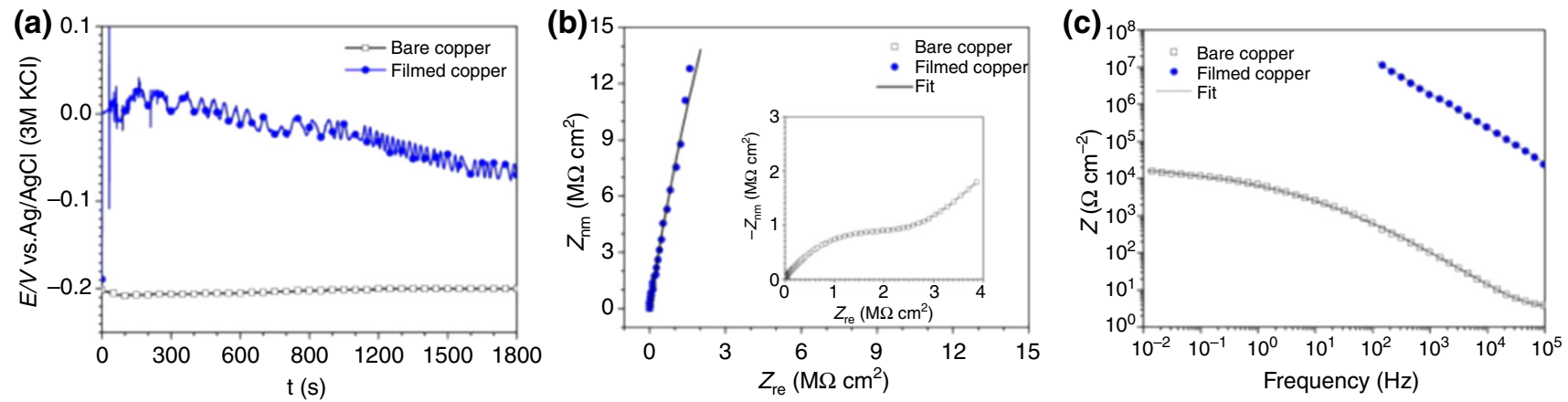

Fig. 13: (a) OCP vs time for bare copper and superhydrophobic copper surfaces. (b) and (c) are Nyquist plots and Bode plots from EIS measurements, respectively. The large OCP fluctuation and the unmeasurably high impedance are both attributed to the nonconductive air cushion trapped in the microstructure ${ }^{106}$

(Fig. 13a). ${ }^{106,108,109}$ In EIS measurements, this is often seen as a dominant capacitive behavior, and occasionally unmeasurably high impedance moduli in the lowfrequency range (Figs. 13b and 13c). ${ }^{34,105,106}$ Figures $14 \mathrm{a}-14 \mathrm{c}$ shows the typical equivalent circuits describing the electrochemical process on superhydrophobic surfaces. ${ }^{27,29,30,34,60,62,106,110-114}$ In many cases, they can be simply replaced by Fig. 14d because of the highly insulating property of the superhydrophobic surface. The superior inhibitive effect of superhydrophobic surface can be also more directly observed from the suppressed corrosion current density from polarization curves, by which the corrosion rate can be estimated.

Once water has penetrated the air barrier after prolonged immersion, a Cassie contact may be changed to a Wenzel contact and the anticorrosive performance of superhydrophobic surface declines (Fig. 12b). For example, Wang et al. intentionally depleted the trapped air in superhydrophobic copper surfaces by a solvent replacing method from ethanol to water. ${ }^{34}$ Compared to a regular superhydrophobic surface, the deaerated superhydrophobic surface formed a Wenzel contact with the surrounding water. Without the air barrier, both polarization curves and EIS spectra confirmed a dramatically lower corrosion resistance. Ejenstam et al. prepared alkyl ketene dimer (AKD) wax coatings with a lotus-like surface (high contact angle, low $\mathrm{CAH}$ ) and a rose-like surface (high contact angle, high $\mathrm{CAH}$ ) and tracked the variations of their EIS spectra for up to 17 days. ${ }^{108}$ Compared to a lotuslike surface, water can easily penetrate into the microscaled structures on the rose-like surface. Therefore, despite a similarly high contact angle, the absence of air pockets resulted in a rapid decay of impedance modulus for the rose-like surface when immersed during the EIS studies.

Obviously, the effectiveness of superhydrophobic surfaces to protect immersed structures largely depends on the underwater stability of the air films which 
(a)

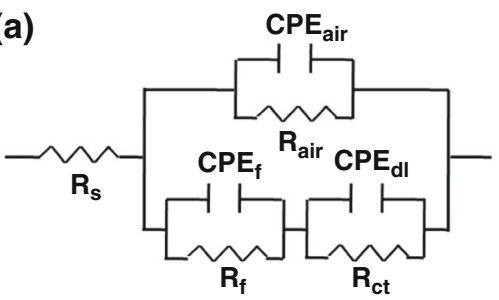

(c)

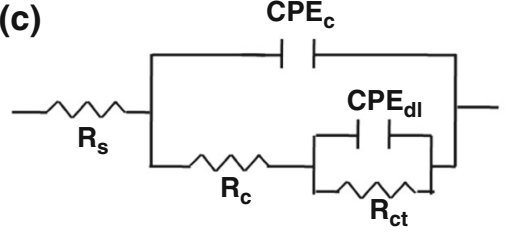

(b)

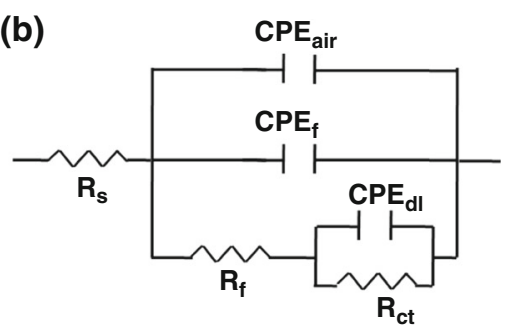

(d)

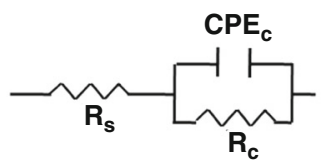

Fig. 14: Typical equivalent circuits used for superhydrophobic surfaces. $C P E_{a i r}$ and $R_{\text {air }}$ are constant phase element and resistant for trapped air, respectively. $C P E_{f}$ and $R_{f}$ are constant phase element and resistant for superhydrophobic film, respectively. $C P E_{c}$ and $R_{c}$ are constant phase element and resistant for combined surface (air + superhydrophobic film), respectively. CPE $_{d l}$ is the constant phase element for double layer and $\mathbf{R}_{\mathrm{ct}}$ is charge transfer resistant

rapidly decays with increasing hydraulic pressure, ${ }^{115-117}$ flow, ${ }^{118}$ or salinity ${ }^{119}$ of the surrounding fluids. In fact, almost none of the surfaces developed so far have shown an acceptably long underwater superhydrophobicity for practical applications. ${ }^{117}$ Most of them failed within hours and rarely for days. $\mathrm{Xu}$ et al. have shown that the air film trapped under water in a specially designed trench can be retained for $>1200 \mathrm{~h}$ if maintained at a shallow position and with minimal environmental fluctuation. ${ }^{11}$ However, actual corrosion environments hardly meet such requirements.

To achieve superhydrophobicity, highly porous microstructures with large surface areas are often needed. However, this makes the microstructure itself hardly a durable barrier against a corrosive environment. $\mathrm{Yu}$ et al. compared the $\mathrm{TiO}_{2} / \mathrm{ZnO}$ structures with hydrophobic and superhydrophobic surfaces. ${ }^{120}$ The high porosity and good self-cleaning performance of superhydrophobic $\mathrm{TiO}_{2} / \mathrm{ZnO}$ layer showed better anticorrosive capability in the atmospheric environment. However, if immersed, the porous superhydrophobic layer was more vulnerable to water ingress which led to lower anticorrosive performance than that of a hydrophobic layer. In Fig. 15, EIS results indicated that the enhanced anticorrosive performance was only shown when the droplet kept on rolling off the surface. Furthermore, despite the undeniable importance of surface roughness in hydrophobicity, further research is required to fully clarify the relationship between surface roughness of the microstructures and the resulting anticorrosive properties. This is partly due to the fact that the precise control of surface roughness is difficult through most of the current methods for preparing superhydrophobic anticorrosive surfaces. $^{121}$

\section{Future trends in development of superhydrophobic surfaces with long-lasting corrosion resistance}

\section{Improving the stability of superhydrophobic surfaces}

Essentially, all superhydrophobic surfaces are to a certain extent capable of withstanding chemical attacks in aqueous acid, alkaline, or salt solutions. Nevertheless, because of their delicate porous structures required for superhydrophobicity, most of these surfaces do not have high mechanical durability. ${ }^{52}$ When damaged by external forces, their surface hydrophobicity could be easily reduced. Integrity of the coatings may be also damaged, which causes defects, such as cracks, and results in decreased protectiveness against corrosion. To this end, improving the mechanical robustness has become one of the key issues in the development of superhydrophobic surfaces with longlasting corrosion resistance. Xiu et al. demonstrated that the superhydrophobicity of silica surface with micro and nanoscale hierarchical structure survived better after mechanical abrasion than that of a nanostructure only superhydrophobic surface (Fig. 16). ${ }^{122}$ After abrasion, only the nanostructures on the peaks of the microstructures were removed. The nanostructures at the bottom were largely preserved, which was critical for retaining the surface superhydrophobicity.

Interfacial strength among nanostructures, binding materials, and substrate is another critical factor affecting the mechanical durability of superhydrophobic structures. By UV irradiation, Zhao et al. introduced covalent crosslinks within silica nanoparticlespolyelectrolyte multilayers and between the multilayers and the substrate. ${ }^{123}$ The obtained surface demon- 
(a)

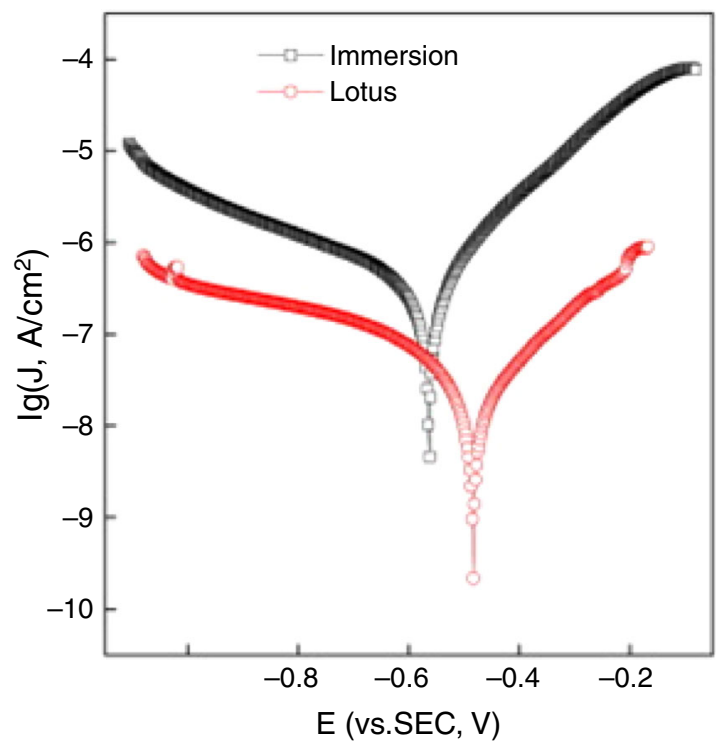

(b)

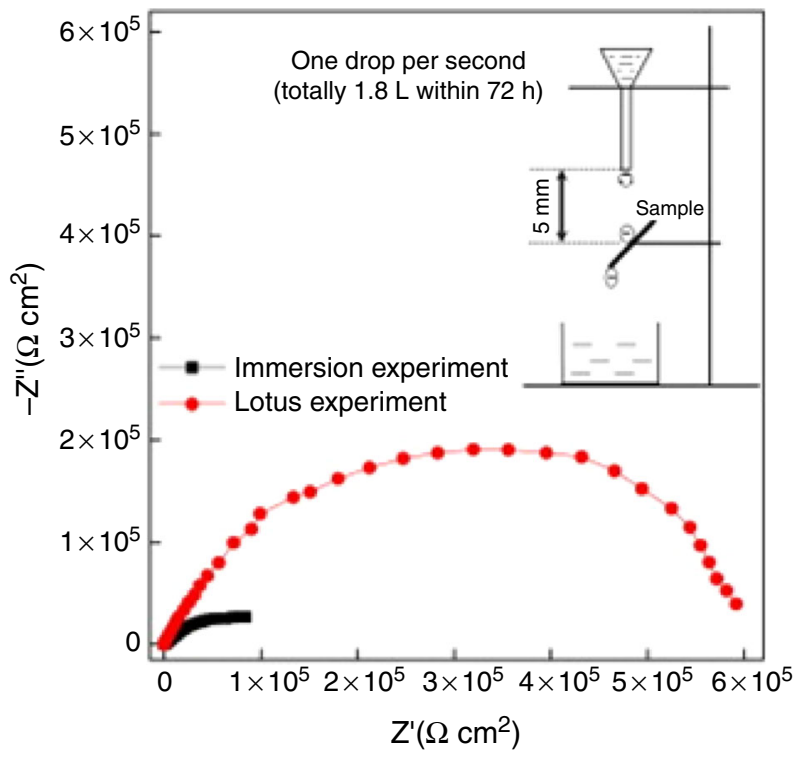

Fig. 15: Polarization curves (a) and Nyquist plots (b) of the superhydrophobic $\mathrm{TiO}_{2} / \mathrm{ZnO}$ surface after $72 \mathrm{~h}$ immersion and the Lotus experiments. The inset is the instrument for Lotus experiment ${ }^{120}$

(a)
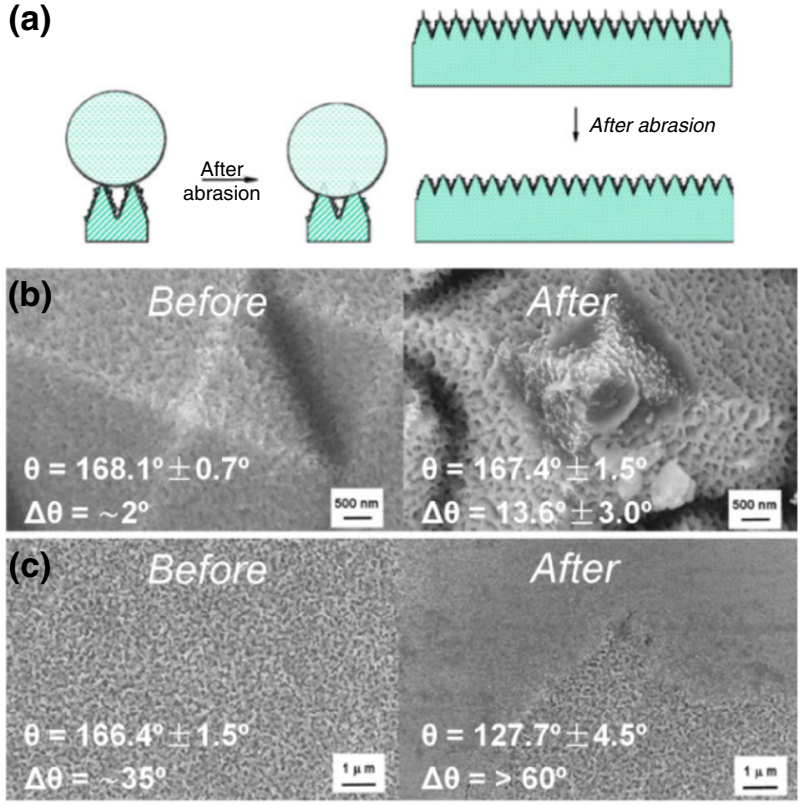

Fig. 16: (a) Illustration of water droplet on Si with two-scale structures before and after abrasion; (b) SEM morphology, static contact angle, and contact angle hysteresis of Si with two-scale structures before and after abrasion; (c) SEM morphology, static contact angle, and contact angle hysteresis of $\mathrm{Si}$ with nanostructures before and after abrasion $^{122}$

strated durable superhydrophobicity against repeated machine washes. Another very important but essentially more straightforward strategy is to create superhydrophobic structures directly from bulk materials.
$\mathrm{Xu}$ et al. used micromeshes as a template to press against softened LDPE at $\sim 105^{\circ} \mathrm{C} .{ }^{124}$ Upon cooling and removing the template, a superhydrophic LDPE surface with three-dimensional orderly microposts was formed without any chemical modification (Fig. 17). After grinding for 5500 times at a speed of $8 \mathrm{~cm} / \mathrm{s}$, the surface still retained its superhydrophobic property. A templating process sequentially using nanoporous anodic aluminum oxide and microporous silicon was applied to fabricate a hierarchical superhydrophobic surface out of hydrophilic metallic glass. ${ }^{125}$ Repeated grinding showed that such a superhydrophobic structure had excellent mechanical durability.

\section{Self-healing capability of superhydrophobic surfaces}

Self-healing materials are an emerging class of smart materials that when damaged are capable of autonomous repair or can be repaired under external stimuli, such as heat, light, and solvents. ${ }^{126,127}$ Ideally, incorporating self-healing functionality to superhydrophobic surfaces would remarkably improve their longevity and hence the capability of long-term corrosion protection. The self-healing of hydrophobicity can be realized by replenishing materials of low surface energy at the surface. For example, through chemical vapor deposition, a large amount of FAS molecules were deposited on the surface and into the bulk of porous polyelectrolyte multilayers to prepare the superhydrophobic surface. ${ }^{128}$ When the hydrophobicity was impaired, the FAS molecules stored inside the micro/nanopores can automatically migrate to the surface and heal the 

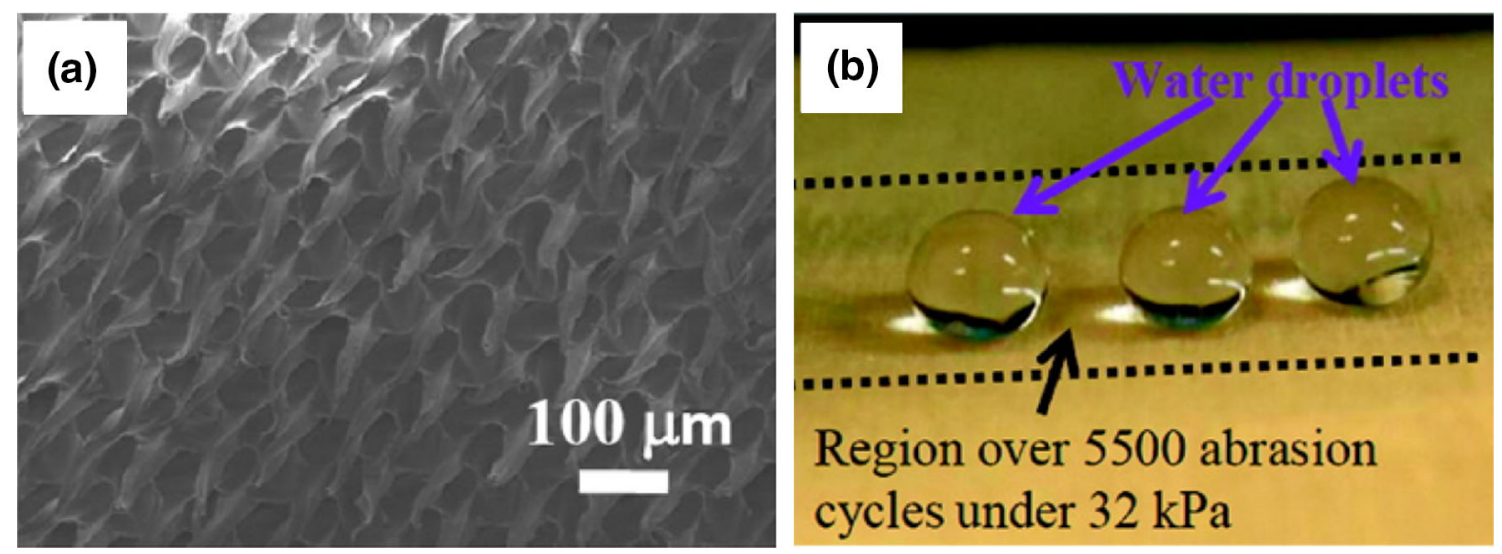

Fig. 17: (a) SEM images of LDPE surfaces fabricated by templating and lamination; (b) water droplets on a surface after mechanical abrasion ${ }^{124}$

(a)

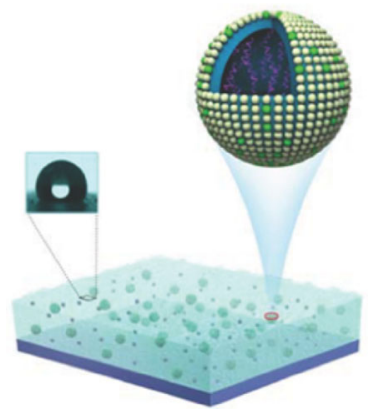

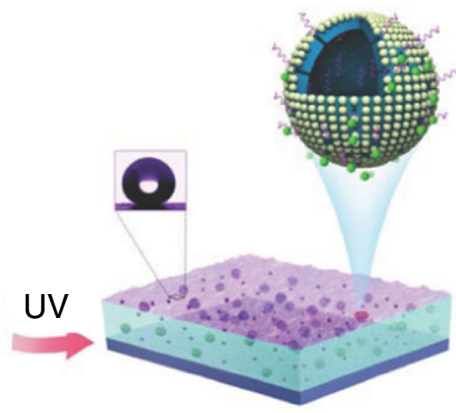

(b)

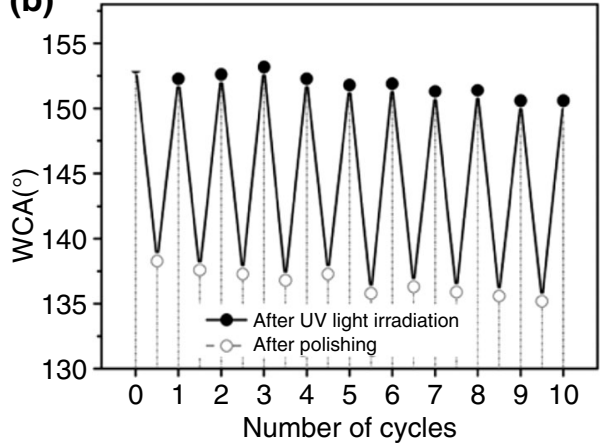

Fig. 18: (a) Schematic illustration of recovery of surface hydrophobic materials by UV treatment; (b) Change of contact angle as a function of repeated polishing and UV weathering cycles $^{130}$

superhydrophobicity. Similarly, mesoporous silica microparticles were used to store the molecules of octadecylamine, endowing the superhydrophobic surface with a self-healing function. ${ }^{129}$ FAS-loaded UVresponsive capsules were synthesized by Pickering emulsion polymerization with $\mathrm{TiO}_{2}$ and $\mathrm{SiO}_{2}$ nanoparticles and were incorporated into polysiloxane latex to prepare a water-based superhydrophobic coating (Fig. 18). ${ }^{130}$ Upon mechanical damages or organic contamination, the superhydrophobicity can be conveniently repaired by exposure to UV lights which decomposed the $\mathrm{TiO}_{2}$ nanoparticles and released FAS. The coating remained superhydrophobic after more than $2160 \mathrm{~h}$ in an outdoor environment, which was potentially interesting for many practical applications.

Compared with replenishing surface hydrophobic materials, the healing of superhydrophobicity by restoring the rough microstructures is even more difficult. $^{52}$ Manna et al. reported a unique example of self-healing superhydrophobic surface based on chemical crosslinking of branched poly(ethyleneimine) and poly(vinyl-4,4-dimethylazlactone) multilayers, followed by reaction with hydrophobic n-decylamine molecules. ${ }^{131}$ When compressed, the surface lost this hydrophobicity as a result of the damaged microstructures. However, liquids, such as water and acid, were capable of restoring such structure by swelling of coating, thereby restoring the superhydrophobic performance (Fig. 19). More interestingly, the recovery of superhydrophobicity was more efficient by more acidic solution which would protonate the amine groups in poly(ethyleneimine) for faster swelling.

Although not reported yet, the use of shape memory polymers (SMP) would represent another promising solution to endow self-healing function to superhydrophobic anticorrosive surfaces. SMPs are stimulisensitive materials which are able to recover to their original shapes from temporarily deformed shapes by heat, light, or other environmental triggers. ${ }^{132,133}$ Chen and Yang have fabricated an SMP-based superhydrophobic surface based on epoxy micropillar arrays using a templating method (Fig. 20). ${ }^{134}$ On the deformed surface, water droplets adopted Wenzel state and the superhydrophobicity was lost. In contrast, water droplets adopted Cassie mode on the recovered micropillar surface which regains its superhydrophobicity simply by heating to $80^{\circ} \mathrm{C}$. 

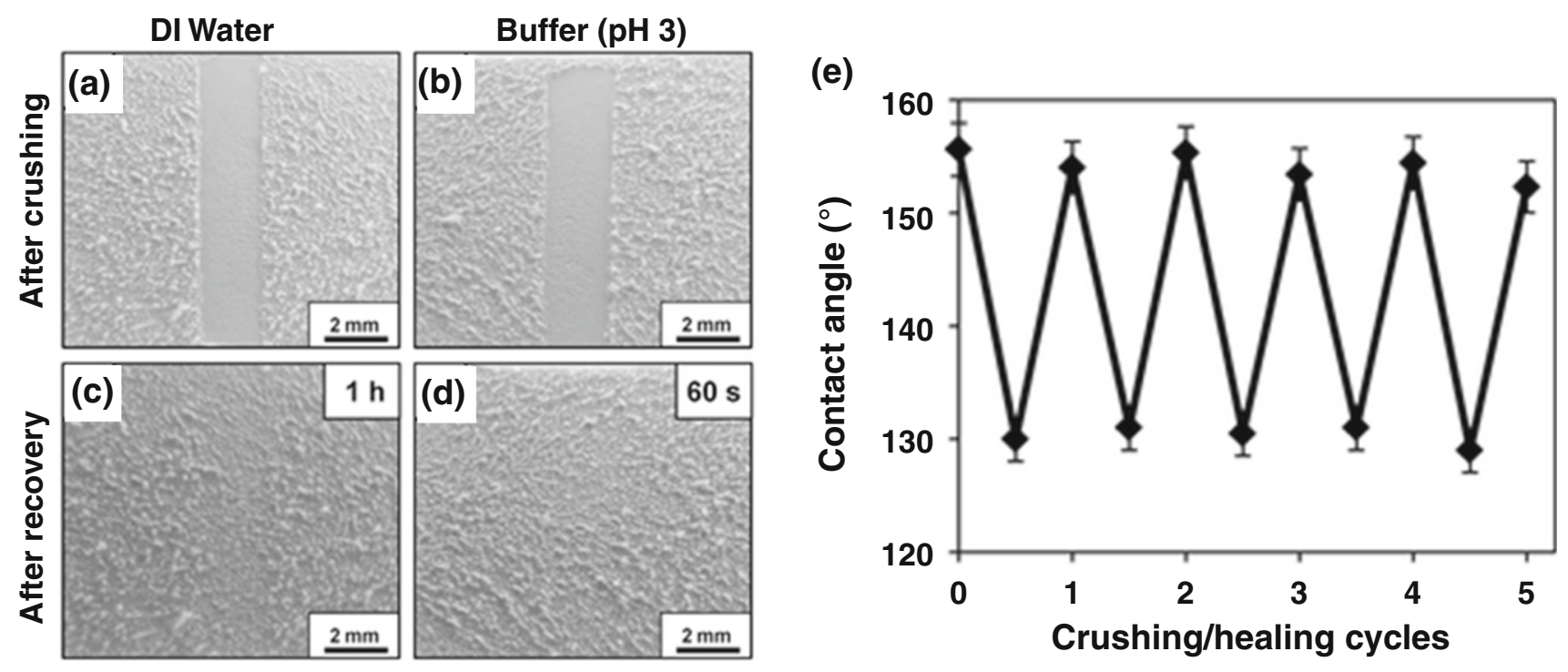

Fig. 19: Recovery of crushed microstructures by treatment with DI water (a, c) and acid buffer (b, d); (e) Contact angle v. number of crushing/healing cycles applied ${ }^{131}$
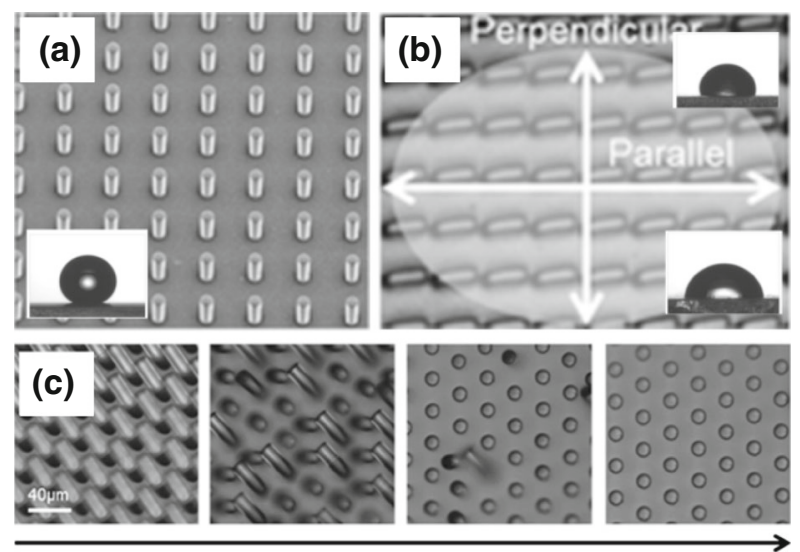

Recovery time $(\sim 50 \mathrm{~s})$

Fig. 20: (a) superhydrophobic SMP pillar surface; (b) Deformed SMP pillar surface; (c) Shape memory process at $80^{\circ} \mathrm{C}^{134}$

\section{Inhibitor-containing superhydrophobic coatings}

In corrosion researches, a major class of self-healing coatings are prepared with corrosion inhibitors as fillers. The damages to these surfaces can trigger the leaching of embedded corrosion inhibitors which form strongly adherent films at the defects via complexation with corrosion products such as metallic ions. ${ }^{135}$ Therefore, instead of repairing surface hydrophobicity or bulk integrity, the self-healing regime in this case takes effect by the autonomous inhibition of corrosion reactions. Besides direct doping, ${ }^{136-138}$ corrosion inhibitors were more frequently stored in micro/nanocapsules ${ }^{139-143}$ and fibers ${ }^{144}$ and then mixed in coating matrix for more efficient or $\mathrm{pH}$-responsive

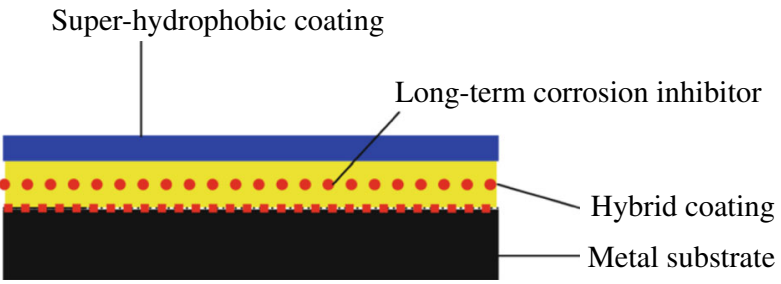

Fig. 21: An ideal model of multiple hybrid coatings for corrosion protection of metals ${ }^{149}$

releases. A list of excellent articles can be referred to for the reviews of inhibitor-containing self-healing anticorrosive coatings. ${ }^{145-148}$ Zheng et al. proposed an ideal model of multiple hybrid anticorrosive coatings which consisted of inhibitor-doped primer and superhydrophobic topcoat (Fig. 21). ${ }^{49}$ The surface superhydrophobicity resists corrosive species, such as water and ions within a certain time. Even if the superhydrophobic topcoat is damaged, prolonged release of corrosion inhibitors from the underlying primer can still confer active corrosion protection at the defected region.

\section{Conclusions}

Superhydrophobic surfaces represent a significant technological breakthrough in recent studies over corrosion protection of metals. By reducing water contacting area and time or forming additional air barrier films, superhydrophobic surfaces can minimize the interaction between metal substrates and aqueous corrosive species and produce superior anticorrosive 
performances. Of the reported fabrication methods, most are laboratory-scaled and not yet ready for production of large superhydrophobic surfaces that could be potentially interesting for many real applications. This can be attributed to the complexity of hierarchical micro/nanostructures as well as the costly low surface energy materials. For these superhydrophobic surfaces, another major concern is their capability of demonstrating long-lasting corrosion resistance. Thus, future works are still required with focuses on enhancing stability of superhydrophobic structures. Alternatively, self-healing functionalities and/or corrosion inhibitors may be introduced for the design of smart superhydrophobic surfaces that can repair their anticorrosive performance autonomously or with minimal external intervention.

Acknowledgments This work is supported by National Natural Science Foundation of China (No. 51401018) and the National Basic Research Program of China (973 Program project, No. 2014CB643300).

Open Access This article is distributed under the terms of the Creative Commons Attribution 4.0 International License (http://creativecommons.org/licenses/by/4.0/), which permits unrestricted use, distribution, and reproduction in any medium, provided you give appropriate credit to the original author(s) and the source, provide a link to the Creative Commons license, and indicate if changes were made.

\section{References}

1. Barthlott, W, Neinhuis, C, "Purity of the Sacred Lotus, or Escape from Contamination in Biological Surfaces." Planta, 202 (1) 1-8 (1997)

2. Sun, T, Feng, L, Gao, X, Jiang, L, "Bioinspired Surfaces with Special Wettability." Acc. Chem. Res., 38 (8) 644-652 (2005)

3. Gao, X, Yan, X, Yao, X, Xu, L, Zhang, K, Zhang, J, Yang, B, Jiang, L, "The Dry-Style Antifogging Properties of Mosquito Compound Eyes and Artificial Analogues Prepared by Soft Lithography." Adv. Mater., 19 (17) 2213-2217 (2007)

4. Feng, L, Zhang, Y, Xi, J, Zhu, Y, Wang, N, Xia, F, Jiang, L, "Petal Effect: A Superhydrophobic State with High Adhesive Force." Langmuir, 24 (8) 4114-4119 (2008)

5. Wang, S, Jiang, L, "Definition of Superhydrophobic States." Adv. Mater., 19 (21) 3423-3424 (2007)

6. Li, J, Liu, X, Ye, Y, Zhou, H, Chen, J, "Fabrication of Superhydrophobic $\mathrm{CuO}$ Surfaces with Tunable Water Adhesion." J. Phys. Chem. C, 115 (11) 4726-4729 (2011)

7. Li, J, Jing, Z, Zha, F, Yang, Y, Wang, Q, Lei, Z, "Facile Spray-Coating Process for the Fabrication of Tunable Adhesive Superhydrophobic Surfaces with Heterogeneous Chemical Compositions Used for Selective Transportation of Microdroplets with Different Volumes." ACS Appl. Mater. Inter., 6 (11) 8868-8877 (2014)

8. Li, X-M, Reinhoudt, D, Crego-Calama, M, "What do we Need for a Superhydrophobic Surface? A Review on the Recent Progress in the Preparation of Superhydrophobic Surfaces." Chem. Soc. Rev., 36 (8) 1350-1368 (2007)
9. Roach, P, Shirtcliffe, NJ, Newton, MI, "Progess in Superhydrophobic Surface Development." Soft Matter, 4 (2) 224 240 (2008)

10. Nosonovsky, M, Bhushan, B, "Superhydrophobic Surfaces and Emerging Applications: Non-adhesion, Energy, Green Engineering." Curr. Opin. Colloid In., 14 (4) 270-280 (2009)

11. Yan, Y, Gao, N, Barthlott, W, "Mimicking Natural Superhydrophobic Surfaces and Grasping the Wetting Process: A Review on Recent Progress in Preparing Superhydrophobic Surfaces." Adv. Colloid Interfac., 169 (2) 80-105 (2011)

12. Nishimoto, S, Bhushan, B, "Bioinspired Self-Cleaning Surfaces with Superhydrophobicity, Superoleophobicity, and Superhydrophilicity." RSC Adv., 3 (3) 671-690 (2013)

13. Darmanin, T, De Givenchy, ET, Amigoni, S, Guittard, F, "Superhydrophobic Surfaces by Electrochemical Processes." Adv. Mater., 25 (10) 1378-1394 (2013)

14. Liu, K, Tian, Y, Jiang, L, "Bio-inspired Superoleophobic and Smart Materials: Design, Fabrication, and Application." Prog. Mater. Sci., 58 (4) 503-564 (2013)

15. Wen, L, Tian, Y, Jiang, L, "Bioinspired Super-Wettability from Fundamental Research to Practical Applications." Angew. Chem. Int. Edit., 54 (11) 3387-3399 (2015)

16. Young, T, "An Essay on the Cohesion of Fluids." Philos. Trans. Roy. Soc. Lond., 95 65-87 (1805)

17. Wenzel, RN, "Resistance of Solid Surfaces to Wetting by Water." Ind. Eng. Chem., 28 (8) 988-994 (1936)

18. Cassie, ABD, Baxter, S, "Wettability of Porous Surfaces." T. Faraday Soc., 40 546-551 (1944)

19. Sørensen, PA, Kiil, S, Dam-Johansen, K, Weinell, C, "Anticorrosive Coatings: A Review." J. Coat. Technol. Res., 6 (2) 135-176 (2009)

20. Ji, W-G, Hu, J-M, Liu, L, Zhang, J-Q, Cao, C-N, "Improving the Corrosion Performance of Epoxy Coatings by Chemical Modification with Silane Monomers." Surf. Coat. Technol., 201 (8) 4789-4795 (2007)

21. Shon, M, Kwon, H, "Comparison of Surface Modification with Amino Terminated Polydimethylsiloxane and Amino Branched Polydimethylsiloxane on the Corrosion Protection of Epoxy Coating." Corros. Sci., 51 (3) 650-657 (2009)

22. Díaz, I, Chico, B, De La Fuente, D, Simancas, J, Vega, J, Morcillo, M, "Corrosion Resistance of New Epoxy-Siloxane Hybrid Coatings. A Laboratory Study." Prog. Org. Coat., 69 (3) 278-286 (2010)

23. Çanak, TÇ, Serhatll, IE, "Synthesis of Fluorinated Urethane Acrylate Based UV-Curable Coatings." Prog. Org. Coat., 76 (2) 388-399 (2013)

24. Wankhede, RG, Morey, S, Khanna, A, Birbilis, N, "Development of Water-Repellent Organic-Inorganic Hybrid SolGel Coatings on Aluminum Using Short Chain Perfluoro Polymer Emulsion.” Appl. Surf. Sci., 283 1051-1059 (2013)

25. Hutzinger, O, The Handbook of Environmental Chemistry. Springer, Berlin, 1980

26. Tuteja, A, Choi, W, Mabry, JM, McKinley, GH, Cohen, RE, "Robust Omniphobic Surfaces." P. Natl. Acad. Sci. USA, 105 (47) 18200-18205 (2008)

27. Liu, T, Yin, Y, Chen, S, Chang, X, Cheng, S, "SuperHydrophobic Surfaces Improve Corrosion Resistance of Copper in Seawater." Electrochim. Acta, 52 (11) 3709-3713 (2007)

28. Wang, Y, Wang, W, Zhong, L, Wang, J, Jiang, Q, Guo, X, "Super-hydrophobic Surface on Pure Magnesium Substrate by Wet Chemical Method." Appl. Surf. Sci., 256 (12) $3837-$ 3840 (2010)

29. Ishizaki, T, Masuda, Y, Sakamoto, M, "Corrosion Resistance and Durability of Superhydrophobic Surface Formed on Magnesium Alloy Coated with Nanostructured Cerium 
Oxide Film and Fluoroalkylsilane Molecules in Corrosive $\mathrm{NaCl}$ Aqueous Solution.' Langmuir, 27 (8) 4780-4788 (2011)

30. Wang, P, Zhang, D, Qiu, R, "Liquid/Solid Contact Mode of Super-Hydrophobic Film in Aqueous Solution and Its Effect on Corrosion Resistance." Corros. Sci., 54 77-84 (2012)

31. Guo, F, Su, X, Hou, G, Li, P, "Bioinspired Fabrication of Stable and Robust Superhydrophobic Steel Surface with Hierarchical Flowerlike Structure.' Colloids Surface A, 401 61-67 (2012)

32. Song, J, Lu, Y, Huang, S, Liu, X, Wu, L, Xu, W, “A Simple Immersion Approach for Fabricating Superhydrophobic Mg Alloy Surfaces.” Appl. Surf. Sci., 266 445-450 (2013)

33. Liang, J, Hu, Y, Fan, Y, Chen, H, "Formation of Superhydrophobic Cerium Oxide Surfaces on Aluminum Substrate and Its Corrosion Resistance Properties." Surf. Interface Anal., 45 (8) 1211-1216 (2013)

34. Wang, P, Zhang, D, Qiu, R, Wu, J, "Super-Hydrophobic Metal-Complex Film Fabricated Electrochemically on Copper as a Barrier to Corrosive Medium." Corros. Sci., 83 317-326 (2014)

35. Zhao, L, Liu, Q, Gao, R, Wang, J, Yang, W, Liu, L, “Onestep Method for the Fabrication of Superhydrophobic Surface on Magnesium Alloy and Its Corrosion Protection, Antifouling Performance." Corros. Sci., 80 177-183 (2014)

36. Liu, C, Su, F, Liang, J, Huang, P, "Facile Fabrication of Superhydrophobic Cerium Coating with Micro-nano Flower-Like Structure and Excellent Corrosion Resistance." Surf. Coat. Tech., 258 580-586 (2014)

37. Wei, G, Wang, Z, Zhao, X, Feng, J, Wang, S, Zhang, J, An, C, "A Facile Approach to Fabricate Superhydrophobic and Corrosion Resistant Surface." Mater. Res. Express, 2 (1) 015501 (2015)

38. Zhou, M, Pang, X, Wei, L, Gao, K, "Insitu Grown Superhydrophobic Zn-Al Layered Double Hydroxides Films on Magnesium Alloy to Improve Corrosion Properties." Appl. Surf. Sci., 337 172-177 (2015)

39. Ganesh, VA, Raut, HK, Nair, AS, Ramakrishna, S, “A Review on Self-Cleaning Coatings." J. Mater. Chem., 21 (41) 16304-16322 (2011)

40. Guo, Z, Liu, W, Su, B-L, "Superhydrophobic Surfaces: from Natural to Biomimetic to Functional." J. Colloid. Interf. Sci., 353 (2) 335-355 (2011)

41. Chen, X, Yuan, J, Huang, J, Ren, K, Liu, Y, Lu, S, Li, H, "Large-Scale Fabrication of Superhydrophobic Polyurethane/Nano- $\mathrm{Al}_{2} \mathrm{O}_{3}$ Coatings by Suspension Flame Spraying for Anti-corrosion Applications." Appl. Surf. Sci., 311 864-869 (2014)

42. Wang, J, Chen, X, Kang, Y, Yang, G, Yu, L, Zhang, P, "Preparation of Superhydrophobic Poly (Methyl Methacrylate)-Silicon Dioxide Nanocomposite Films." Appl. Surf. Sci., 257 (5) 1473-1477 (2010)

43. Liu, K, Zhang, M, Zhai, J, Wang, J, Jiang, L, "Bioinspired Construction of Mg-Li Alloys Surfaces with Stable Superhydrophobicity and Improved Corrosion Resistance." Appl. Phys. Lett., 92 (18) 183103 (2008)

44. Liu, L, Xu, F, Ma, L, "Facile Fabrication of a Superhydrophobic $\mathrm{Cu}$ Surface via a Selective Etching of HighEnergy Facets." J. Phys. Chem. C, 116 (35) 18722-18727 (2012)

45. Li, L, Breedveld, V, Hess, DW, "Creation of Superhydrophobic Stainless Steel Surfaces by Acid Treatments and Hydrophobic Film Deposition." ACS Appl. Mater. Inter., 4 (9) 4549-4556 (2012)

46. Wang, Z, Li, Q, She, Z, Chen, F, Li, L, Zhang, X, Zhang, P, "Facile and Fast Fabrication of Superhydrophobic Surface on Magnesium Alloy." Appl. Surf. Sci., 271 182-192 (2013)
47. Liu, Y, Yin, X, Zhang, J, Wang, Y, Han, Z, Ren, L, "Biomimetic Hydrophobic Surface Fabricated by Chemical Etching Method from Hierarchically Structured Magnesium Alloy Substrate." Appl. Surf. Sci., 280 845-849 (2013)

48. Zang, D, Zhu, R, Zhang, W, Wu, J, Yu, X, Zhang, Y, "Stearic Acid Modified Aluminum Surfaces with Controlled Wetting Properties and Corrosion Resistance." Corros. Sci., 83 86-93 (2014)

49. Li, X, Zhang, Q, Guo, Z, Shi, T, Yu, J, Tang, M, Huang, X, "Fabrication of Superhydrophobic Surface with Improved Corrosion Inhibition on 6061 Aluminum Alloy Substrate." Appl. Surf. Sci., 342 76-83 (2015)

50. Lv, D, Ou, J, Xue, M, Wang, F, "Stability and Corrosion Resistance of Superhydrophobic Surface on Oxidized Aluminum in $\mathrm{NaCl}$ Aqueous Solution." Appl. Surf. Sci., 333 163-169 (2015)

51. Wang, N, Xiong, D, Deng, Y, Shi, Y, Wang, K, “Mechanically Robust Superhydrophobic Steel Surface with Antiicing, UV-Durability and Corrosion Resistance Properties." ACS Appl. Mater. Inter., 7 6260-6272 (2015)

52. Xue, C-H, Ma, J-Z, "Long-Lived Superhydrophobic Surfaces." J. Mater. Chem. A, 1 (13) 4146-4161 (2013)

53. Su, F, Yao, K, Liu, C, Huang, P, "Rapid Fabrication Of Corrosion Resistant and Superhydrophobic Cobalt Coating by a One-Step Electrodeposition." J. Electrochem. Soc., 160 (11) D593-D599 (2013)

54. Feng, L, Zhang, H, Wang, Z, Liu, Y, "Superhydrophobic Aluminum Alloy Surface: Fabrication, Structure, and Corrosion Resistance." Colloids Surf. A, 441 319-325 (2014)

55. Guo, X, Xu, S, Zhao, L, Lu, W, Zhang, F, Evans, DG, Duan, X, "One-Step Hydrothermal Crystallization of a Layered Double Hydroxide/Alumina Bilayer Film on Aluminum and Its Corrosion Resistance Properties." Langmuir, 25 (17) 9894-9897 (2009)

56. Wang, J, Li, D, Liu, Q, Yin, X, Zhang, Y, Jing, X, Zhang, M, "Fabrication of Hydrophobic Surface with Hierarchical Structure on Mg Alloy and Its Corrosion Resistance." Electrochim. Acta, 55 (22) 6897-6906 (2010)

57. Li, L, Zhang, Y, Lei, J, He, J, Lv, R, Li, N, Pan, F, “A Facile Approach to Fabricate Superhydrophobic Zn Surface and Its Effect on Corrosion Resistance." Corros. Sci., 85 174182 (2014)

58. Ou, J, Hu, W, Xue, M, Wang, F, Li, W, "Superhydrophobic Surfaces on Light Alloy Substrates Fabricated by a Versatile Process and Their Corrosion Protection." ACS Appl. Mater. Inter., 5 (8) 3101-3107 (2013)

59. Gao, R, Liu, Q, Wang, J, Zhang, X, Yang, W, Liu, J, Liu, L, "Fabrication of Fibrous Szaibelyite with Hierarchical Structure Superhydrophobic Coating on AZ31 Magnesium Alloy for Corrosion Protection." Chem. Eng. J., $241352-$ 359 (2014)

60. Fan, Y, Chen, Z, Liang, J, Wang, Y, Chen, H, "Preparation of Superhydrophobic Films on Copper Substrate for Corrosion Protection." Surf. Coat. Technol., 244 1-8 (2014)

61. Wang, Z, Gong, J, Ma, J, Xu, J, "In Situ Growth of Hierarchical Boehmite on 2024 Aluminum Alloy Surface as Superhydrophobic Materials." RSC Adv., 4 (28) 14708 14714 (2014)

62. He, T, Wang, Y, Zhang, Y, Xu, T, Liu, T, "SuperHydrophobic Surface Treatment as Corrosion Protection for Aluminum in Seawater." Corros. Sci., 51 (8) 1757-1761 (2009)

63. Zhang, F, Chen, S, Dong, L, Lei, Y, Liu, T, Yin, Y, "Preparation of Superhydrophobic Films on Titanium as Effective Corrosion Barriers." Appl. Surf. Sci., 257 (7) 2587-2591 (2011) 
64. Yin, B, Fang, L, Tang, A-Q, Huang, Q-L, Hu, J, Mao, J-H, Bai, G, Bai, H, "Novel Strategy in Increasing Stability and Corrosion Resistance for Super-Hydrophobic Coating on Aluminum Alloy Surfaces." Appl. Surf. Sci., 258 (1) 580 585 (2011)

65. Vengatesh, P, Kulandainathan, MA, "Hierarchically Ordered Self-Lubricating Superhydrophobic Anodized Aluminum Surfaces with Enhanced Corrosion Resistance." ACS Appl. Mater. Inter., 7 (3) 1516-1526 (2015)

66. Peng, S, Tian, D, Yang, X, Deng, W, "Highly Efficient and Large-Scale Fabrication of Superhydrophobic Alumina Surface with Strong Stability Based on Self-Congregated Alumina Nanowires." ACS Appl. Mater. Inter., 6 (7) 48314841 (2014)

67. Huang, Q, Yang, Y, Hu, R, Lin, C, Sun, L, Vogler, EA, "Reduced Platelet Adhesion and Improved Corrosion Resistance of Superhydrophobic $\mathrm{TiO}_{2}$-Nanotube-Coated 316L Stainless Steel." Colloids Surf. B, 125 134-141 (2015)

68. Lu, Z, Wang, P, Zhang, D, "Super-Hydrophobic Film Fabricated on Aluminium Surface as a Barrier to Atmospheric Corrosion in a Marine Environment." Corros. Sci., 91 287-296 (2015)

69. Xiao, F, Yuan, S, Liang, B, Li, G, Pehkonen, SO, Zhang, T, "Superhydrophobic $\mathrm{CuO}$ Nanoneedle-Covered Copper Surfaces for Anti-corrosion." J. Mater. Chem. A, 3 (8) 4378-4388 (2015)

70. Jeong, C, Choi, C-H, "Single-Step Direct Fabrication of Pillar-on-Pore Hybrid Nanostructures in Anodizing Aluminum for Superior Superhydrophobic Efficiency." $A C S$ Appl. Mater. Inter., 4 (2) 842-848 (2012)

71. Wang, Z, Li, Q, She, Z, Chen, F, Li, L, "Low-cost and Large-Scale Fabrication Method for an EnvironmentallyFriendly Superhydrophobic Coating on Magnesium Alloy." J. Mater. Chem., 22 (9) 4097-4105 (2012)

72. de Leon, ACC, Pernites, RB, Advincula, RC, "Superhydrophobic Colloidally Textured Polythiophene Film as Superior Anticorrosion Coating." ACS Appl. Mater. Inter., 4 (6) 3169-3176 (2012)

73. She, Z, Li, Q, Wang, Z, Tan, C, Zhou, J, Li, L, "Highly Anticorrosion, Self-Cleaning Superhydrophobic Ni-Co Surface Fabricated on AZ91D Magnesium Alloy." Surf. Coat. Tech., 251 7-14 (2014)

74. Su, F, Yao, K, "Facile Fabrication of Superhydrophobic Surface with Excellent Mechanical Abrasion and Corrosion Resistance on Copper Substrate by a Novel Method." ACS Appl. Mater. Inter., 6 (11) 8762-8770 (2014)

75. Khorsand, S, Raeissi, K, Ashrafizadeh, F, "Corrosion Resistance and Long-Term Durability of Super-Hydrophobic Nickel Film Prepared by Electrodeposition Process." Appl. Surf. Sci., 305 498-505 (2014)

76. Liu, Q, Chen, D, Kang, Z, "One-Step Electrodeposition Process to Fabricate Corrosion Resistant Superhydrophobic Surface on Magnesium Alloy." ACS Appl. Mater. Inter., 7 (3) 1859-1867 (2015)

77. Liu, Y, Li, S, Zhang, J, Liu, J, Han, Z, Ren, L, “Corrosion Inhibition of Biomimetic Super-Hydrophobic Electrodeposition Coatings on Copper Substrate." Corros. Sci., 94 190196 (2015)

78. Rao, AV, Latthe, SS, Mahadik, SA, Kappenstein, C, "Mechanically Stable and Corrosion Resistant Superhydrophobic Sol-Gel Coatings on Copper Substrate." Appl. Surf. Sci., 257 (13) 5772-5776 (2011)

79. Wang, S, Guo, X, Xie, Y, Liu, L, Yang, H, Zhu, R, Gong, J, Peng, L, Ding, W, "Preparation of Superhydrophobic Silica Film on $\mathrm{Mg}-\mathrm{Nd}-\mathrm{Zn}-\mathrm{Zr}$ Magnesium Alloy with Enhanced Corrosion Resistance by Combining Micro-arc Oxidation and Sol-Gel Method." Surf. Coat. Tech., 213 192-201 (2012)

80. Liang, J, Hu, Y, Wu, Y, Chen, H, "Facile Formation of Superhydrophobic Silica-Based Surface on Aluminum Substrate with Tetraethylorthosilicate and Vinyltriethoxysilane as Co-precursor and Its Corrosion Resistant Performance in Corrosive $\mathrm{NaCl}$ Aqueous Solution." Surf. Coat. Tech., 240 145-153 (2014)

81. Wu, L-K, Zhang, X-F, Hu, J-M, "Corrosion Protection of Mild Steel by One-Step Electrodeposition of Superhydrophobic Silica Film." Corros. Sci., 85 482-487 (2014)

82. Motlagh, NV, Birjandi, FC, Sargolzaei, J, Shahtahmassebi, N, "Durable, Superhydrophobic, Superoleophobic and Corrosion Resistant Coating on the Stainless Steel Surface Using a Scalable Method." Appl. Surf. Sci., 283 636-647 (2013)

83. Zhang, K, Wu, J, Chu, P, Ge, Y, Zhao, R, Li, X, “A novel CVD Method for Rapid Fabrication of Superhydrophobic Surface on Aluminum Alloy Coated Nanostructured Cerium-Oxide and Its Corrosion Resistance." Int. J. Electrochem. Sci, 10 6257-6272 (2015)

84. Figueira, R, Silva, C, Pereira, E, "Organic-Inorganic Hybrid Sol-Gel Coatings for Metal Corrosion Protection: A Review of Recent Progress." J. Coat. Technol. Res., 12 (1) 1-35 (2014)

85. Xiu, Y, Hess, DW, Wong, C, "UV-Resistant and Superhydrophobic Self-Cleaning Surfaces Using Sol-Gel Processes.” J. Adhes. Sci. Technol., 22 (15) 1907-1917 (2008)

86. Xu, X, Zhang, Z, Guo, F, Yang, J, Zhu, X, "Fabrication of Superhydrophobic Binary Nanoparticles/PMMA Composite Coating with Reversible Switching of Adhesion and Anticorrosive Property." Appl. Surf. Sci., 257 (16) 70547060 (2011)

87. Weng, CJ, Peng, CW, Chang, CH, Chang, YH, Yeh, JM, "Corrosion Resistance Conferred by Superhydrophobic Fluorinated Polyacrylate-Silica Composite Coatings on Cold-Rolled Steel." J. Appl. Polym. Sci., 126 (S2) E48E55 (2012)

88. Momen, G, Farzaneh, M, "Facile Approach in the Development of Icephobic Hierarchically Textured Coatings as Corrosion Barrier." Appl. Surf. Sci., 299 41-46 (2014)

89. Wang, H, Liu, Z, Wang, E, Yuan, R, Gao, D, Zhang, X, Zhu, Y, "A Robust Superhydrophobic PVDF Composite Coating with Wear/Corrosion-Resistance Properties." Appl. Surf. Sci., 332 518-524 (2015)

90. Qing, Y, Yang, C, Hu, C, Zheng, Y, Liu, C, "A Facile Method to Prepare Superhydrophobic Fluorinated Polysiloxane/ZnO Nanocomposite Coatings with Corrosion Resistance." Appl. Surf. Sci., 326 48-54 (2015)

91. Cui, Z, Yin, L, Wang, Q, Ding, J, Chen, Q, “A Facile DipCoating Process for Preparing Highly Durable Superhydrophobic Surface with Multi-scale Structures on Paint Films." J. Colloid Interf. Sci., 337 (2) 531-537 (2009)

92. Lu, Y, Sathasivam, S, Song, J, Crick, CR, Carmalt, CJ, Parkin, IP, "Robust Self-Cleaning Surfaces that Function when Exposed to Either Air or Oil." Science, 347 (6226) 1132-1135 (2015)

93. Qin, D, Xia, Y, Whitesides, GM, "Soft Lithography for Micro-and Nanoscale Patterning." Nat. Protoc., 5 (3) 491$502(2010)$

94. Weng, C-J, Chang, C-H, Peng, C-W, Chen, S-W, Yeh, J-M, Hsu, C-L, Wei, Y, "Advanced Anticorrosive Coatings Prepared from the Mimicked Xanthosoma SagittifoliumLeaf-Like Electroactive Epoxy with Synergistic Effects of Superhydrophobicity and Redox Catalytic Capability." Chem. Mater., 23 (8) 2075-2083 (2011) 
95. Peng, C-W, Chang, K-C, Weng, C-J, Lai, M-C, Hsu, C-H, Hsu, S-C, Hsu, Y-Y, Hung, W-I, Wei, Y, Yeh, J-M, "NanoCasting Technique to Prepare Polyaniline Surface with Biomimetic Superhydrophobic Structures for Anticorrosion Application." Electrochim. Acta, 95 192-199 (2013)

96. Peng, C-W, Chang, K-C, Weng, C-J, Lai, M-C, Hsu, C-H, Hsu, S-C, Li, S-Y, Wei, Y, Yeh, J-M, "UV-curable Nanocasting Technique to Prepare Bio-mimetic Super-Hydrophobic Non-fluorinated Polymeric Surfaces for Advanced Anticorrosive Coatings." Polym. Chem., 4 (4) 926-932 (2013)

97. Chang, K-C, Lu, H-I, Peng, C-W, Lai, M-C, Hsu, S-C, Hsu, M-H, Tsai, Y-K, Chang, C-H, Hung, W-I, Wei, Y, "Nanocasting Technique to Prepare Lotus-Leaf-Like Superhydrophobic Electroactive Polyimide as Advanced Anticorrosive Coatings." ACS Appl. Mater. Inter., 5 (4) 1460-1467 (2013)

98. Chang, C-H, Hsu, M-H, Weng, C-J, Hung, W-I, Chuang, T-L, Chang, K-C, Peng, C-W, Yen, Y-C, Yeh, J-M, "3DBioprinting Approach to Fabricate Superhydrophobic Epoxy/Organophilic Clay as an Advanced Anticorrosive Coating with the Synergistic Effect of Superhydrophobicity and Gas Barrier Properties." J. Mater. Chem. A, 1 (44) 13869-13877 (2013)

99. Chang, K-C, Hsu, M-H, Lu, H-I, Lai, M-C, Liu, P-J, Hsu, C-H, Ji, W-F, Chuang, T-L, Wei, Y, Yeh, J-M, "RoomTemperature Cured Hydrophobic Epoxy/Graphene Composites as Corrosion Inhibitor for Cold-Rolled Steel." Carbon, 66 144-153 (2014)

100. Yang, N, Li, Q, Chen, F, Cai, P, Tan, C, Xi, Z, "A solvingReprecipitation Theory for Self-Healing Functionality of Stannate Coating with a High Environmental Stability." Electrochim. Acta, 174 1192-1201 (2015)

101. Cheng, Y-T, Rodak, DE, "Is the Lotus Leaf Superhydrophobic?" Appl. Phys. Lett., 86 (14) 144101 (2005)

102. Rykaczewski, K, Osborn, WA, Chinn, J, Walker, ML, Scott, JHJ, Jones, W, Hao, C, Yao, S, Wang, Z, "How Nanorough is Rough Enough to Make a Surface Superhydrophobic During Water Condensation?" Soft Matter, 8 (33) 87868794 (2012)

103. Ko, T-J, Her, EK, Shin, B, Kim, H-Y, Lee, K-R, Hong, BK, $\mathrm{Kim}, \mathrm{SH}, \mathrm{Oh}, \mathrm{KH}$, Moon, M-W, "Water Condensation Behavior on the Surface of a Network of Superhydrophobic Carbon Fibers with High-Aspect-Ratio Nanostructures." Carbon, 50 (14) 5085-5092 (2012)

104. Wang, P, Zhang, D, Lu, Z, "Advantage of Super-Hydrophobic Surface as a Barrier Against Atmospheric Corrosion Induced by Salt Deliquescence." Corros. Sci., 90 23-32 (2015)

105. Wang, P, Zhang, D, Qiu, R, Wu, J, Wan, Y, "SuperHydrophobic Film Prepared on Zinc and Its Effect on Corrosion in Simulated Marine Atmosphere." Corros. Sci., 69 23-30 (2013)

106. Wang, P, Zhang, D, Qiu, R, Wan, Y, Wu, J, "Green Approach to Fabrication of a Super-Hydrophobic Film on Copper and the Consequent Corrosion Resistance." Corros. Sci., 80 366-373 (2014)

107. Brandner, BD, Hansson, PM, Swerin, A, Claesson, PM, Wåhlander, M, Schoelkopf, J, Gane, PA, "Solvent Segregation and Capillary Evaporation at a Superhydrophobic Surface Investigated by Confocal Raman Microscopy and Force Measurements." Soft Matter, 7 (3) 1045-1052 (2011)

108. Ejenstam, L, Ovaskainen, L, Rodriguez-Meizoso, I, Wågberg, L, Pan, J, Swerin, A, Claesson, PM, "The Effect of Superhydrophobic Wetting State on Corrosion Protection-The AKD Example." J. Colloid Interf. Sci., 412 56-64 (2013)
109. Qiu, R, Zhang, D, Wang, P, "Superhydrophobic-Carbon Fibre Growth on a Zinc Surface for Corrosion Inhibition." Corros. Sci., 66 350-359 (2013)

110. Liu, T, Chen, S, Cheng, S, Tian, J, Chang, X, Yin, Y, "Corrosion Behavior of Super-Hydrophobic Surface on Copper in Seawater." Electrochim. Acta, 52 (28) 8003-8007 (2007)

111. Ishizaki, T, Hieda, J, Saito, N, Saito, N, Takai, O, "Corrosion Resistance and Chemical Stability of SuperHydrophobic Film Deposited on Magnesium Alloy AZ31 by Microwave Plasma-Enhanced Chemical Vapor Deposition." Electrochim. Acta, 55 (23) 7094-7101 (2010)

112. Yuan, S, Pehkonen, S, Liang, B, Ting, Y, Neoh, K, Kang, E, "Superhydrophobic Fluoropolymer-Modified Copper Surface via surface Graft Polymerisation for Corrosion Protection." Corros. Sci., 53 (9) 2738-2747 (2011)

113. Yu, D, Tian, J, Dai, J, Wang, X, "Corrosion Resistance of Three-Layer Superhydrophobic Composite Coating on Carbon Steel in Seawater." Electrochim. Acta, 97 409-419 (2013)

114. Liu, Y, Yin, X, Zhang, J, Yu, S, Han, Z, Ren, L, “A electroDeposition Process for Fabrication of Biomimetic SuperHydrophobic Surface and Its Corrosion Resistance on Magnesium Alloy." Electrochim. Acta, 125 395-403 (2014)

115. Poetes, R, Holtzmann, K, Franze, K, Steiner, U, "Metastable Underwater Superhydrophobicity." Phys. Rev. Lett., 105 (16) 166104 (2010)

116. Lee, C, Kim, C-J, "Underwater Restoration and Retention of Gases on Superhydrophobic Surfaces for Drag Reduction." Phys. Rev. Lett., 106 (1) 014502 (2011)

117. Xu, M, Sun, G, Kim, C-J, "Infinite Lifetime of Underwater Superhydrophobic States." Phys. Rev. Lett., 113 (13) 136103 (2014)

118. Samaha, MA, Tafreshi, HV, Gad-el-Hak, M, "Influence of Flow on Longevity of Superhydrophobic Coatings." Langmuir, 28 (25) 9759-9766 (2012)

119. Ochanda, FO, Samaha, MA, Tafreshi, HV, Tepper, GC, Gad-el-Hak, M, "Salinity Effects on the Degree of Hydrophobicity and Longevity for Superhydrophobic Fibrous Coatings." J. Appl. Polym. Sci., 124 (6) 5021-5026 (2012)

120. Yu, D, Tian, J, "Superhydrophobicity: Is it Really Better than Hydrophobicity on Anti-corrosion?" Colloids Surface A, 445 75-78 (2014)

121. Zhang, D, Li, H, Chen, X, Qian, H, Li, X, "Effect of Surface Microstructures on Hydrophobicity and Barrier Property of Anticorrosive Coatings Prepared by Soft Lithography." Adv. Mater. Sci. Eng. (2014). doi:10.1155/ 2014/342184

122. Xiu, Y, Liu, Y, Hess, DW, Wong, C, "Mechanically Robust Superhydrophobicity on HIERARCHICALLY STRUCTURED Si Surfaces." Nanotechnology, 21 (15) 155705 (2010)

123. Zhao, Y, Xu, Z, Wang, X, Lin, T, "Photoreactive AzidoContaining Silica Nanoparticle/Polycation Multilayers: Durable Superhydrophobic Coating on Cotton Fabrics." Langmuir, 28 (15) 6328-6335 (2012)

124. Xu, QF, Mondal, B, Lyons, AM, "Fabricating Superhydrophobic Polymer Surfaces with Excellent Abrasion Resistance by a Simple Lamination Templating Method." ACS Appl. Mater. Inter., 3 (9) 3508-3514 (2011)

125. Ma, J, Zhang, X, Wang, D, Zhao, D, Ding, D, Liu, K, Wang, W, "Superhydrophobic Metallic Glass Surface with Superior Mechanical Stability and Corrosion Resistance." Appl. Phys. Lett., 104 (17) 173701 (2014)

126. Wu, DY, Meure, S, Solomon, D, "Self-healing Polymeric Materials: A Review of Recent Developments." Prog. Polym. Sci., 33 (5) 479-522 (2008) 
127. Yang, Y, Urban, MW, "Self-Healing Polymeric Materials." Chem. Soc. Rev., 42 (17) 7446-7467 (2013)

128. Li, Y, Li, L, Sun, J, "Bioinspired Self-Healing Superhydrophobic Coatings." Angew. Chem. Int. Edit., 122 (35) 6265-6269 (2010)

129. Liu, Q, Wang, X, Yu, B, Zhou, F, Xue, Q, “Self-healing Surface Hydrophobicity by Consecutive Release of Hydrophobic Molecules from Mesoporous Silica." Langmuir, 28 (13) 5845-5849 (2012)

130. Chen, K, Zhou, S, Yang, S, Wu, L, "Fabrication of AllWater-Based Self-Repairing Superhydrophobic Coatings Based on UV-Responsive Microcapsules." Adv. Funct. Mater., 25 (7) 1035-1041 (2015)

131. Manna, U, Lynn, DM, "Restoration of Superhydrophobicity in Crushed Polymer Films by Treatment with Water: Self-Healing and Recovery of Damaged Topographic Features Aided by an Unlikely Source." Adv. Mater., 25 (36) 5104-5108 (2013)

132. Behl, M, Lendlein, A, "Shape-Memory Polymers." Mater. Today, 10 (4) 20-28 (2007)

133. Xie, T, "Recent Advances in Polymer Shape Memory." Polymer, 52 (22) 4985-5000 (2011)

134. Chen, CM, Yang, S, "Directed Water Shedding on HighAspect-Ratio Shape Memory Polymer Micropillar Arrays." Adv. Mater., 26 (8) 1283-1288 (2014)

135. Finšgar, M, Milošev, I, "Inhibition of Copper Corrosion by 1, 2, 3-Benzotriazole: A Review." Corros. Sci., 52 (9) 27372749 (2010)

136. Zheludkevich, M, Tedim, J, Freire, C, Fernandes, S, Kallip, S, Lisenkov, A, Gandini, A, Ferreira, M, "Self-Healing Protective Coatings with "Green" Chitosan Based Prelayer Reservoir of Corrosion Inhibitor." J. Mater. Chem., 21 (13) 4805-4812 (2011)

137. Carneiro, J, Tedim, J, Fernandes, S, Freire, C, Silvestre, A, Gandini, A, Ferreira, M, Zheludkevich, M, "ChitosanBased Self-Healing Protective Coatings Doped with Cerium Nitrate for Corrosion Protection of Aluminum Alloy 2024." Prog. Org. Coat., 75 (1) 8-13 (2012)

138. Aramaki, K, "Self-Healing Mechanism of an Organosiloxane Polymer Film Containing Sodium Silicate and Cerium (III) Nitrate for Corrosion of Scratched Zinc Surface in 0.5 M NaCl." Corros. Sci., 44 (7) 1621-1632 (2002)
139. Shchukin, DG, Zheludkevich, M, Yasakau, K, Lamaka, S, Ferreira, MG, Moehwald, H, "Layer-by-Layer Assembled Nanocontainers for Self-Healing Corrosion Protection." Adv. Mater., 18 (13) 1672-1678 (2006)

140. Borisova, D, Akçakayıran, D, Schenderlein, M, Möhwald, H, Shchukin, DG, "Nanocontainer-Based Anticorrosive Coatings: Effect of the Container Size on the Self-Healing Performance." Adv. Funct. Mater., 23 (30) 3799-3812 (2013)

141. Li, GL, Schenderlein, M, Men, Y, Möhwald, H, Shchukin, DG, "Monodisperse Polymeric Core-Shell Nanocontainers for Organic Self-Healing Anticorrosion Coatings." $A d v$. Mater. Inter., 1 (1) 1300019 (2014)

142. Plawecka, M, Snihirova, D, Martins, B, Szczepanowicz, K, Warszynski, P, Montemor, M, "Self Healing Ability of Inhibitor-Containing Nanocapsules Loaded in Epoxy Coatings Applied on Aluminium 5083 and Galvanneal Substrates." Electrochim. Acta, 140 282-293 (2014)

143. Snihirova, D, Lamaka, SV, Cardoso, MM, Condeço, JA, Ferreira, HE, de Fatima Montemor, M, "pH-Sensitive Polymeric Particles with Increased Inhibitor-Loading Capacity as Smart Additives for Corrosion Protective Coatings for AA2024." Electrochim. Acta, 145 123-131 (2014)

144. Yabuki, A, Kawashima, A, Fathona, IW, "Self-Healing Polymer Coatings with Cellulose Nanofibers Served as Pathways for the Release of a Corrosion Inhibitor." Corros. Sci., 85 141-146 (2014)

145. Hughes, AE, Cole, IS, Muster, TH, Varley, RJ, “Designing Green, Self-Healing Coatings for Metal Protection." NPG Asia Mater., 2 (4) 143-151 (2010)

146. García, S, Fischer, H, van Der Zwaag, S, "A Critical Appraisal of the Potential of Self Healing Polymeric Coatings." Prog. Org. Coat., 72 (3) 211-221 (2011)

147. Shchukin, DG, "Container-Based Multifunctional SelfHealing Polymer Coatings." Polym. Chem., 4 (18) 48714877 (2013)

148. Montemor, M, "Functional and Smart Coatings for Corrosion Protection: A Review of Recent Advances." Surf. Coat. Technol., 258 17-37 (2014)

149. Zheng, S, Li, J, "Inorganic-Organic Sol Gel Hybrid Coatings for Corrosion Protection of Metals." J. Sol-Gel. Sci. Technol., 54 (2) 174-187 (2010) 